\title{
Diaminothiadiazoles - Building Blocks for Macroheterocycles ${ }^{\otimes}$
}

\author{
Elena A. Danilova, Tat'yana V. Melenchuk, Olga N. Trukhina, \\ and Mikhail K. Islyaikin ${ }^{\circledR}$ \\ Ivanovo State University of Chemistry and Technology, 7, Engels Av., 153000, Ivanovo, Russia \\ @Corresponding authorE-mail:islyaikin@isuct.ru
}

\begin{abstract}
Syntheses and properties of 2,5-diamino-1,3,4-thiadiazole, 3,5-diamino-1,2,4-thiadiazole and 3-N-alkyl-5-amino2-imino-1,3,4-thiadiazolines - building blocks for macroheterocyclic compounds are discussed in this review. The convenient methods of their synthesis were elaborated and peculiarities of their geometrical structure were discussed. The mechanism of 3,5-diamino-1,2,4-thiadiazole formation from 2-imino-4-thiobiuret was simulated by quantum chemistry methods at the level of Density Functional Theory (DFT).
\end{abstract}

Keywords: $S, N$-Containing heterocycles, diaminothiadiazoles, 2-imino-4-thiobiuret, 3-alkyl-5-amino-2-imino-1,3,4thiadiazolines, DFT.

\section{Аиаминотиадиазолы - исходные соединения Аля макрогетероциклов $\otimes$}

\author{
Е.А. Аанилова, Т.В. Меленчук, О.Н. Трухина, М.К. Исляйкин ${ }^{@}$ \\ Ивановский государственный химико-технологический университет, пр. Ф.Энгельса, 7, 153000, Иваново, Россия \\ @E-mail: islyaikin@isuct.ru
}

\begin{abstract}
Приведен обзор по синтезу, свойствам 2,5-диамино-1,3,4-тиадиазола, 3,5-диамино-1,2,4-тиадиазола и 3-N-алкил-5-амино-2-имино-1,3,4-тиадиазолинов, представляющих интерес для получения макрогетероциклических соединений. Предложены удобные способы их получения, рассмотрены особенности геометрического строения. С помощью методов квантовой химии, основанных на теории функиионала плотности, проведено моделирование механизма образования 3,5-диамино-1,2,4-тиадиазола.
\end{abstract}

Ключевые слова: $S, N$-Замещенные гетероциклы, диаминотиадиазолы, 2-имино-4-тиобиурет, 3-алкил-5-амино2-имино-1,3,4-тиадиазолины, теория функционала плотности.

\section{Введение}

В органической химии в разные годы проводились и в настоящее время проводятся многочисленные исследования, связанные с разработкой методов синтеза и функционализации гетероциклических соединений, обладающих потенциальной биологической активностью и являющихся исходными соединениями для получения разнообразных макрогетероциклов. В связи с этим наибольший интерес представляют диаминоазолы. ${ }^{[1-12]}$

Пятичленные гетероароматические соединения, имеющие в цикле не менее двух гетероатомов, из кото-

$\otimes$ This contribution is dedicated to professor Vasilij Fedorovich Borodkin on occasion of his $100^{\text {th }}$ Anniversary.

$\otimes$ Статья посвящена 100-летнему юбилею профессора Василия Фёдоровича Бородкина. рых, по крайней мере, один - атом азота, а также би- и полициклические соединения, включающие азольный цикл, принято называть азолами. ${ }^{[13]}$ Основные представители - оксазол, тиазол, имидазол, изоксазол, изотиазол, пиразол, сим-триазол, тетразол; из конденсированных систем - бензимидазол, бензотиазол, бензотриазол.

Многие производные азолов являются природными биологически активными веществами (витамины $\mathrm{B}_{1}$ и $\mathrm{B}_{12}$ ), синтетическими лекарственными препаратами (амидопирин, анальгин, гистидин, гистамин, сульфатиазол и др.).

В последнее время все большее внимание уделяется гетероциклическим соединениям, содержащим в цикле, наряду с атомами азота, атом серы. Значительный интерес к этим соединениям вызван использованием их для получения медицинских препаратов: ацетазоламида, диакарба, этазола, тизанидина и др. ${ }^{[14,15]}$ Кроме того, 
аминотиазолы применяются в качестве промежуточных продуктов в производстве красителей, ${ }^{[16,17]}$ а также в аналитических целях. ${ }^{[18]}$

В зависимости от расположения атомов азота и серы в пятичленном кольце можно выделить следующие тиадиазолы: 1,2,3-тиадиазол (1), 1,2,4-тиадиазол (2), 1,2,5-тиадиазол (3) и 1,3,4-тиадиазол (4):<smiles>c1csnn1</smiles>

1

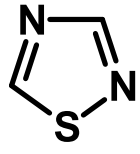

2<smiles>c1cnsn1</smiles>

3<smiles>c1nncs1</smiles>

4
Тиадиазолы наряду с тиофеном, тиазолами и другими пятичленными циклами моно- и диазолов обладают ароматической системой, включающей $6 \pi$-электронов. В то же время по физическим и химическим свойствам они близки диазолам, у которых вместо атома серы присутствует метиленовая группировка. ${ }^{[18]}$

С точки зрения влияния гетероатома на электронное и геометрическое строение макроциклической системы наиболее интересными представляются 1,2,4-тиадиазол (2) и 1,3,4-тиадиазол (4).

Из всех изомерных тиадиазолов на сегодняшний день наиболее изучены 1,3,4-тиадиазолы. ${ }^{[19]}$ Они чувствительны к сильным основаниям, в результате действия которых наблюдается раскрытие цикла, что напоминает свойства других азолов, в частности 1,3,4-оксадиазолов. ${ }^{\text {[20] }}$

Для незамещенного 1,3,4-тиадиазола не известно ни одной реакции электрофильного замещения. Его нитрование не идет, а в случае 2-фенил-1,3,4-тиадиазола образуются продукты, содержащие нитрогруппу в фенильном заместителе. ${ }^{[20]}$ В тоже время амино-1,3,4тиадиазолы вступают в реакции, характерные для ароматических аминов. Они легко диазотируются с последующим замещением диазогруппы.

Диаминотиадиазолы применяются в качестве прекурсоров синтеза макрогетероциклических соединений.

\section{2,5-Диамино-1,3,4-тиадиазол}

Наиболее распространенным методом получения замещенных 1,3,4-тиадиазолов является циклизация соответствующих карбомоилтиосемикарбазидов под действием ацилирующих агентов с последующей дегидратацией полученных продуктов фосфорной, серной кислотой или фосфорным ангидридом ${ }^{[21]}$ (Схема 1).

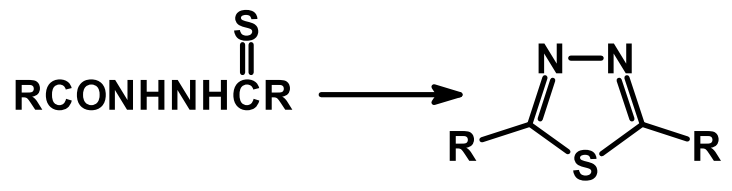

где $\mathrm{R}=\mathrm{NH}_{2}, \mathrm{Alk}, \mathrm{Ar}$

\section{Схема 1.}

При обработке дитиомочевины и ее замещенных соляной кислотой, фосгеном и другими реагентами также образуются тиадиазолы, которые в начале были ошибочно описаны как триазолы. Однако, впоследствии

\section{$\stackrel{\mathrm{H}_{2} \mathrm{NCNHNHCNH}}{\mathrm{S}} \stackrel{\mathrm{HCl}, \mathrm{t}}{\longrightarrow}$}

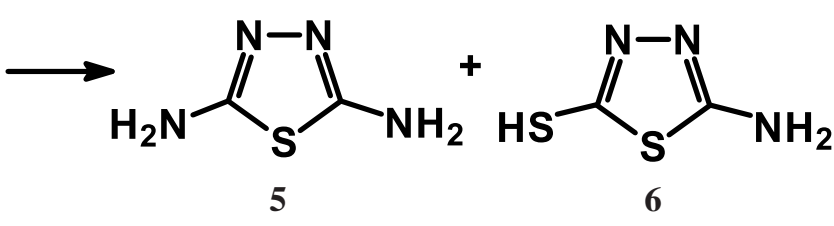

Схема 2.

было показано, ${ }^{[22]}$ что это различные замещенные 1,3,4-тиадиазола 5 и 6 (Схема 2).

Практического применения описанные выше методы не нашли в виду того, что карбомоилтиосемикарбазиды труднодоступны, а выход целевого продукта в обоих случаях невысок.

Анализ литературных данных показал, что более удобным способом получения соединения 5 является окислительная конденсация дитиомочевины ${ }^{[23]}$ (Схема 3):

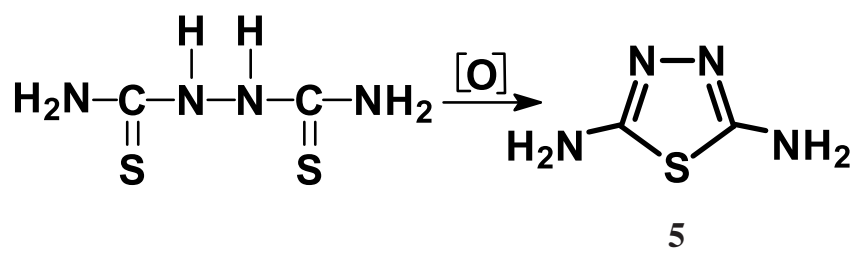

Схема 3.

Сущность метода заключается в окислении дитиомочевины 3\% раствором пероксида водорода. Избыток перекиси разрушается барботированием сероводорода через реакционную массу, выделившаяся сера отделяется фильтрованием. После частичного упаривания раствора выпадают белые кристаллы 5 с невысоким выходом 40-43 \%.

Нередко вместо белых кристаллов наблюдалось образование окрашенных продуктов, которые по своим физико-химическим свойствам не соответствовали 5. ${ }^{[23]}$ Долгое время строение этих продуктов оставалось неясным. Высказывалось предположение, ${ }^{[23,24]}$ что появление окраски может быть вызвано присутствием азосоединений.

Нами было установлено, что образованию этого вещества способствует серная кислота, которая присутствует в пероксиде водорода. В связи с этим был получен монокристалл 5а и его структура выявлена методом РСА. ${ }^{1}$ Кристалл 5а $\mathrm{C}_{4} \mathrm{H}_{10} \mathrm{~N}_{8} \mathrm{O}_{4} \mathrm{~S}_{3}$ размером 0,20x0,20x0,10 $\mathrm{MM}^{3}$ моноклинный, пространственная группа симметрии $C 2 / c$ : параметры элементарной ячейки: $\mathrm{a}=11,6225(14)$, $\mathrm{b}=9,2006(12), \mathrm{c}=10,7084(12) \AA, \quad \beta=91,184(4)^{\circ}$, $\mathrm{V}=1144,8(2) \AA^{3}, \rho_{\text {выч }}=1,917 \mathrm{мг} / \mathrm{M}^{3}, Z=4, \mathrm{~F}(000)=680$, $\mathrm{T}=100(2) \mathrm{K}$. Фрагмент кристаллической структуры 5а представлен на Рисунке 1.

Рентгеноструктурное исследование показало, что соединение 5а является сульфатом 2,5-диамино-3H1,3,4-тиадиазолиния. Структурные единицы кристалла

${ }^{1}$ РСА выполнен в лаборатории рентгено-структурного анали-
за Мадридского автономного университета, Мадрид, Испания 


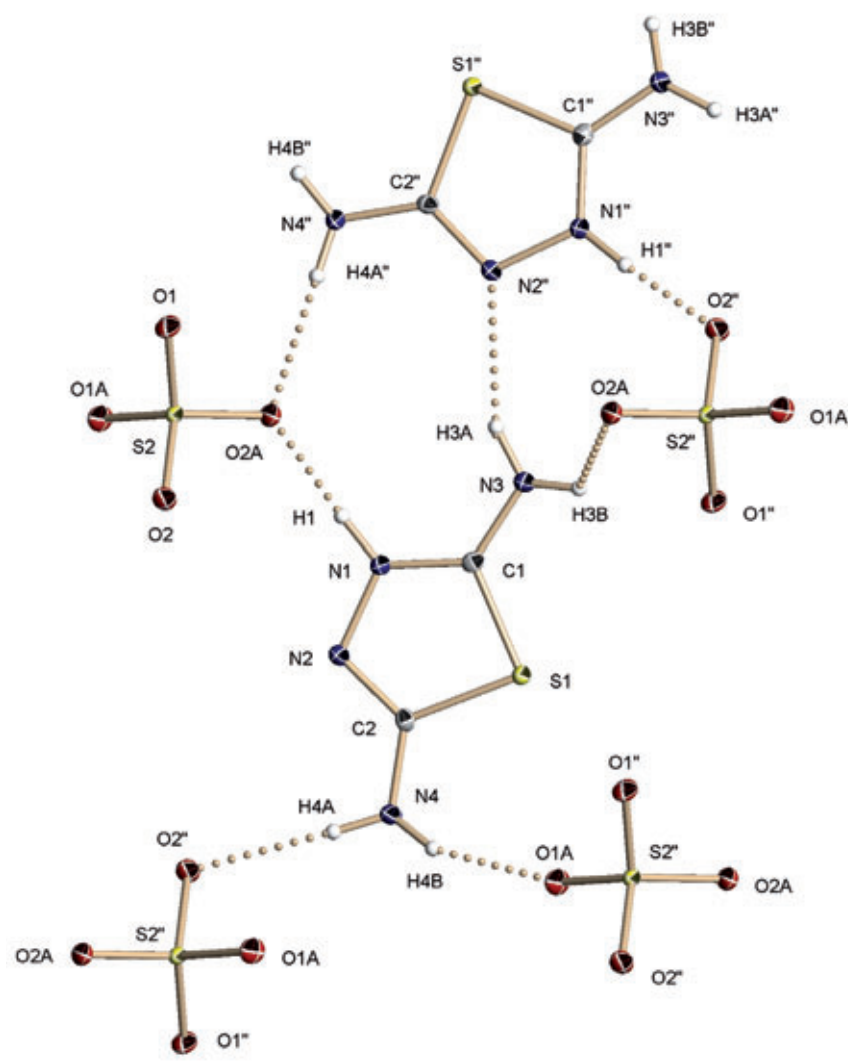

Рисунок 1. Фрагмент кристаллической структуры соединения $\mathbf{5 a .}$

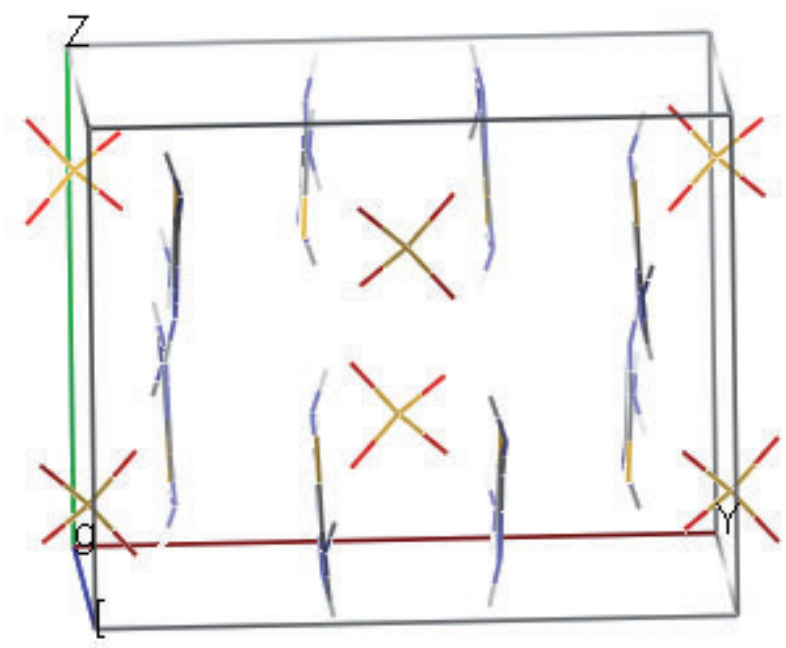

Рисунок 2. Упаковка молекул в 5 а. объединены между собой в стопки водородными связями NH‥О трех типов, что приводит к образованию надмолекулярных структур в виде «сэндвича» (Рисунок 2).

Геометрические характеристики катиона $\mathrm{C}_{2} \mathrm{H}_{5} \mathrm{~N}_{3} \mathrm{~S}^{+}$ отличаются от ранее опубликованных для основания $5^{[25]}$ (Рисунок 3) и совпадают с таковыми для солей, полученных в результате непосредственного взаимодействия 2,5-диамино-1,3,4-тиадиазола с серной, ${ }^{[26]}$ кремнефторводородной ${ }^{[27]}$ и хлороводородной ${ }^{[28]}$ кислотами.

5а охарактеризовано данными электронной, ИК спектроскопии, масс-спектрометрии и данными элементного анализа. В масс-спектре MALDI-TOF обнаружен молекулярный ион $m / z=331[\mathrm{M}+\mathrm{H}]^{+}$, соответствующий составу $\left(\mathrm{C}_{2} \mathrm{H}_{5} \mathrm{~N}_{4} \mathrm{~S}\right)_{2}{ }^{+} \mathrm{SO}_{4}{ }^{2-}$. $\mathrm{B}$ электронном спектре поглощения, измеренным в воде, присутствует одна полоса поглощения с максимумом при 248 нм. В ИК спектре 5а наряду с основными полосами поглощения, присутствующими в спектре 2,5-диамино1,3,4-тиадиазола, обнаружены полосы поглощения в области 1130 и $610 \mathrm{~cm}^{-1}$, характеризующие колебания связей в неорганическом анионе $\mathrm{SO}_{4}{ }^{2-}$.

Таким образом, при взаимодействии дитиомочевины с пероксидом водорода, содержащим примеси серной кислоты, наряду с целевым продуктом - 2,5-диамино1,3,4-тиадиазолом, вероятнее всего образуется сульфат 2,5-диамино-3H-1,3,4-тиадиазолиния, а не азосоединение, о котором упоминается в литературе. ${ }^{[23,24]}$

Полученные результаты показывают, что протонирование идет по атому азота, находящемуся в 3 положении гетероцикла и который, таким образом, выступает в качестве нуклеофильного центра.

Нами было изучено влияние концентрации пероксида водорода на выход 5. Использование 26\% $\mathrm{H}_{2} \mathrm{O}_{2}$ в совокупности с аналитическими методами контроля позволило повысить выход соединения 5 до $79-98 \% .^{[29,30]}$

\section{3-Алкил-5-амино-2-имино-1,3,4-тиадиазолинь}

В 1929 году Штолле и Ференбах ${ }^{[31]}$ сделали предположение, что 2,5-диамино-1,3,4-тиадиазол может существовать в трех формах: 2,5-диамино1,3,4-тиадиазольной $\quad$ (5), 2-имино-5-амино-1,3,4тиадиазолиновой $\quad(5 \mathbf{b})$ и 2,5-диимино- $1,3,4-$ тиадиазолидиновой (5c) (Схема 4).
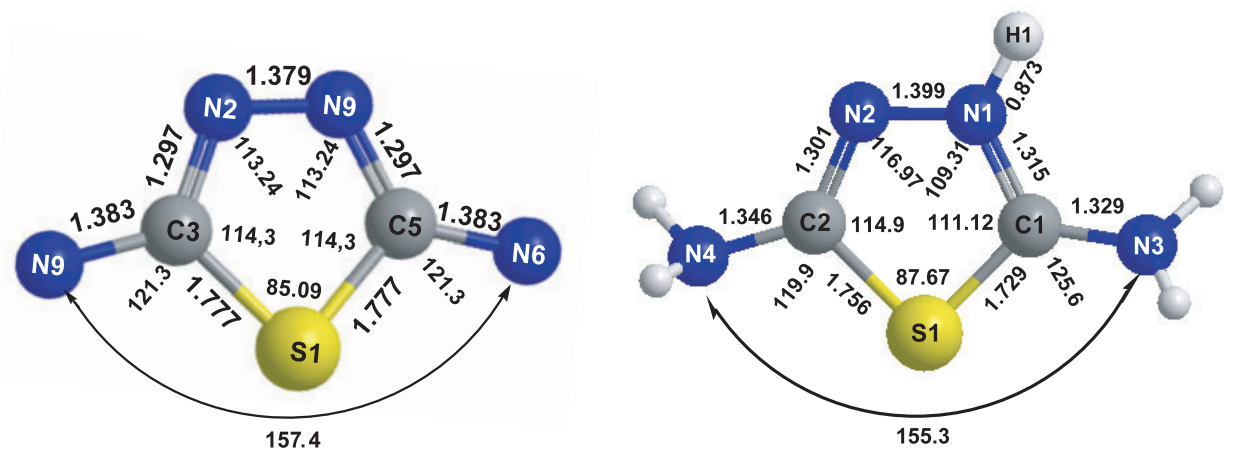

Рисунок 3. Длины связей $(\AA)$ и валентные углы $\left(^{\circ}\right)$ в молекулах 3,5 -диамино- $1,2,4-$-тиадиазола $(\mathbf{5})^{[27]}$ и катиона 5a по данным РСА. 
<smiles>C#CC#C</smiles>

5<smiles>N=c1[nH]nc(N)s1</smiles>

$5 b$<smiles>N=c1[nH][nH]c(=N)s1</smiles>

$5 \mathbf{c}$

Схема 4.<smiles>CC(C)CC(C)C</smiles>

7, 7a - Alk $=\mathrm{C}_{4} \mathrm{H}_{9}, \mathbf{i}-n-\mathrm{AlkB}, \mathrm{MeOH}, 24$ час, кип. ii - $\mathrm{NH}_{3}$ водн.

Схема 5.

Однако эти выводы не были подтверждены экспериментально. Утверждалось, ${ }^{[32,33]}$ что при ацилировании 5 в реакцию вступают иминогруппы в 3- и 4- положениях. Фромм ${ }^{[34]}$ получил противоположные результаты. Он показал, что ацилирование идет по аминогруппам, находящимся при 2 и 5 углеродных атомах. Позднее было показано, что при диазотировании 5 в концентрированной соляной кислоте образуется только монодиазониевая соль, которая при сочетании с фенолом дает азосоединение. ${ }^{[33]}$ Однако конденсация 5 с бензальдегидом, фенилизотиоцианатом и цианом проходит лишь по одной аминогруппе. Так, взаимодействием $S$-метил-1,4-дифенилизотиосемикарбазида с фенилизоцианатом был получен 2-амино-4-фенил-5фенилимино-1,3,4-тиазолидин. ${ }^{[35,36]}$

Таким образом, было показано, что 2-амино-5имино-1,3,4-тиадиазолины можно выделить в виде различных производных. ${ }^{[37]}$ В 1977 году была опубликована работа, которая подтвердила ранее выдвинутые гипотезы. ${ }^{[38]}$ Авторам прямым алкилированием 2-амино$1,3,4$-тиадиазола йодистым метилом удалось получить 3-метил-2-имино-1,3,4-тиадиазолин.

Первая публикация по прямому $N$-алкилированию 2,5-диамино-1,3,4-тиадиазола 5 в положение 3 появились в 2001 году. ${ }^{[39]}$ По аналогии с ранее описанной методикой ${ }^{[38]}$ было проведено алкилирование 2,5-диамино1,3,4-тиадиазола бутилбромидом в кипящем $\mathrm{MeOH}$. После обработки водным раствором аммиака был выделен 5-амино-3-бутил-2-имино-1,3,4-тиадиазолин (7) (Схема 5).

Таким образом, циклический атом азота является нуклеофильным центром не только при протонировании, но и при алкилировании. Развивая этот подход, нами был получен ряд новых $N$-алкилзамещенных тиадиазолинов 8 - 12.

Как оказалось, реакция алкилирования проходит достаточно легко и с высоким выходом целевых<smiles>N=c1sc(N)nn1[AlH2]</smiles>

Alk - 8 $\mathrm{C}_{5} \mathrm{H}_{11} ; 9 \mathrm{C}_{10} \mathrm{H}_{21} ; \mathbf{1 0} \mathrm{C}_{12} \mathrm{H}_{25} ; 11 \mathrm{C}_{15} \mathrm{H}_{31} ; 12 \mathrm{C}_{16} \mathrm{H}_{33}$ продуктов. Характеристика полученных соединений ${ }^{[10,30,40]}$ представлена в Таблице 1.

Введение алкильного заместителя увеличивает растворимость 8 - 12 в органических растворителях. Все алкилированные продукты растворяются в спиртах, в бензоле, хлороформе, дихлорметане, не растворяются в воде.

Строение полученных соединений установлено на основании данных элементного анализа, массспектрометрии, ИК и ${ }^{1} \mathrm{H}$ ЯМР спектроскопии. Так, в масс-спектре соединения 8 присутствуют сигналы с $m / z=185$, отвечающий молекулярному иону $[\mathrm{M}+\mathrm{H}]^{+}$, а также продуктов фрагментации этого соединения.

В спектре ${ }^{1} \mathrm{H}$ ЯМР соединения 8 уширенный сигнал при 5,92 м.д. характеризует резонанс протона иминогруппы. Синглет при 4,22 м.д. относится к протонам аминогруппы. Два триплета (3,69 и 0,87 м.д.) и два мультиплета (1,68 и 1,27 м.д.) обусловлены резонансом протонов алкильной цепи.

В ИК спектрах синтезированных алкилтиадиазолинов (Рисунок 4) присутствует ряд полос, вызванных

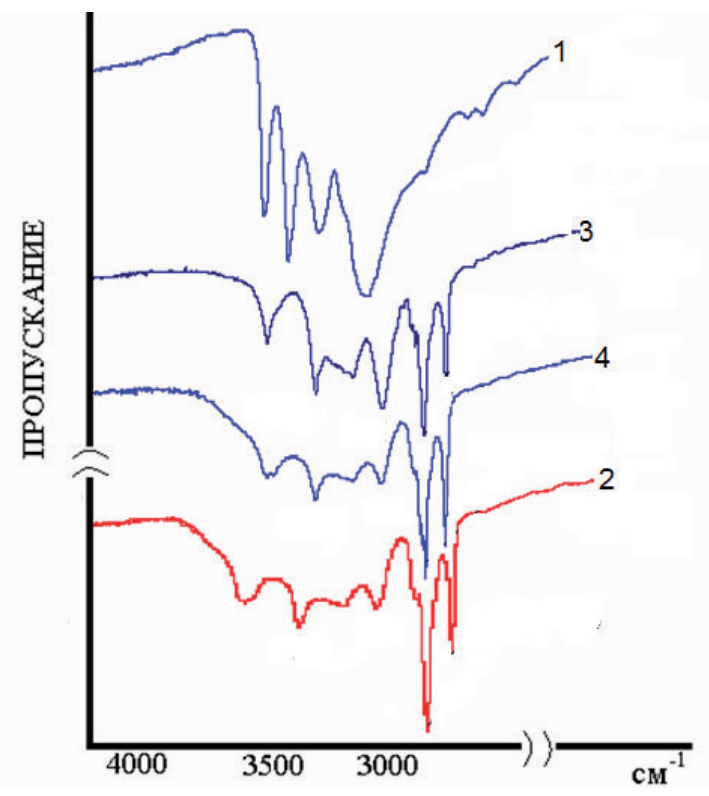

Рисунок 4. ИК спектры соединений в области 4000-2500 $\mathrm{cm}^{-1}$ (таблетка с KBr): 1 - 2,5-диамино-1,3;4тиадиазол (5); 2 - 3-пентил- (8); 3 - 3-децил- (9); 4 - 3-додецилтиадиазолин (10). 
Таблица 1. Основные характеристики 3-алкил-5-амино-2-имино-1,3,4-тиадиазолинов 8 - 12.

\begin{tabular}{|c|c|c|c|c|c|c|c|c|c|c|}
\hline \multirow[b]{2}{*}{$\mathrm{Alk}=$} & \multirow{2}{*}{ 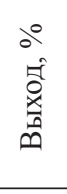 } & \multirow[t]{2}{*}{ Т.пл., ${ }^{\circ} \mathrm{C}$} & \multirow[t]{2}{*}{$R_{\mathrm{f}}^{*}$} & \multicolumn{4}{|c|}{$\begin{array}{c}\text { Данные элементного анализа. } \\
\text { Найдено, \% } \\
\text { Вычислено, \% }\end{array}$} & \multirow[t]{2}{*}{$m / z$} & \multirow{2}{*}{$\begin{array}{l}\lambda_{\max } \\
(\lg \varepsilon), \\
\text { EtOH }\end{array}$} & \multirow[t]{2}{*}{ 'Н ЯМР, м.Д. } \\
\hline & & & & $\mathrm{C}$ & $\mathrm{H}$ & $\mathrm{N}$ & $\mathrm{S}$ & & & \\
\hline $8 \quad \mathrm{C}_{5} \mathrm{H}_{11}$ & 71 & $175-177$ & 0,67 & $\frac{45,07}{45,88}$ & $\frac{6,42}{6,05}$ & $\frac{30,96}{30,57}$ & $\frac{17,28}{17,50}$ & $\begin{array}{l}185 \\
{[\mathrm{M}+\mathrm{H}]^{+}} \\
\mathrm{MM} \\
186,1\end{array}$ & $\begin{array}{l}269 \\
(4,05)\end{array}$ & $\begin{array}{l}5,92(\text { с., } 1 \mathrm{H} ;-\mathrm{NH}) ; 4,22 \\
\left(\text { с., } 2 \mathrm{H} ;-\mathrm{NH}_{2}\right) ; 3,69 \text { (тр., } \\
\left.2 \mathrm{H} ; \mathrm{N}-\mathrm{CH}_{2}-\right) ; 1,68 \text { (с., } \\
\left.2 \mathrm{H} ; \mathrm{N}-\mathrm{CH}_{2}-\mathrm{CH}_{2}-\right) ; 1,27 \\
\left(\text { c., } 2 \mathrm{H} ;-\mathrm{CH}_{2}-\mathrm{CH}_{3}\right) ; 0,87 \\
\left(\text { тр., } 3 \mathrm{H} ;-\mathrm{CH}_{3}\right)\end{array}$ \\
\hline $9 \mathrm{C}_{10} \mathrm{H}_{21}$ & 63 & $182-184$ & 0,75 & $\frac{56,13}{56,43}$ & $\frac{9,77}{9,08}$ & $\frac{22,45}{21,94}$ & $\frac{12,63}{12,55}$ & $\begin{array}{l}255 \\
{[\mathrm{M}+\mathrm{H}]^{+}} \\
\mathrm{MM} \\
256,2\end{array}$ & $\begin{array}{l}271 \\
(3,69)\end{array}$ & $\begin{array}{l}\left.3,39 \text { (тр., } 2 \mathrm{H} ; \mathrm{N}-\mathrm{CH}_{2}^{-}\right) ; \\
\left.1,68 \text { (с., } 2 \mathrm{H} ; \mathrm{N}-\mathrm{CH}_{2}-\mathrm{CH}_{2}-\right) ; \\
\left.1,25 \text { (м., } 14 \mathrm{H} ;-\mathrm{CH}_{2}\right) ; 0,86 \\
\left(-\mathrm{CH}_{3}\right)\end{array}$ \\
\hline $10 \quad \mathrm{C}_{12} \mathrm{H}_{25}$ & 82 & $173-175$ & 0,70 & $\frac{58,82}{59,11}$ & $\frac{9,47}{9,92}$ & $\frac{20,14}{19,70}$ & $\frac{10,89}{11,27}$ & $\begin{array}{l}284 \\
{[\mathrm{M}]^{+}} \\
\mathrm{MM} \\
284,2\end{array}$ & $\begin{array}{l}270 \\
(3,72)\end{array}$ & $\begin{array}{l}4,28\left(\text { с., } 2 \mathrm{H} ;-\mathrm{NH}_{2}\right) ; 3,74 \\
(\text { тр., 2H; N-CH }) ; 0,89 \\
\left(3 \mathrm{H} ;-\mathrm{CH}_{3}\right)\end{array}$ \\
\hline $11 \mathrm{C}_{15} \mathrm{H}_{31}$ & 60 & - & 0,73 & $\frac{61,77}{62,53}$ & $\frac{11,27}{10,49}$ & $\frac{17,47}{17,16}$ & $\frac{9,77}{9,82}$ & $\begin{array}{l}326 \\
{[\mathrm{M}]^{+}} \\
\mathrm{MM} \\
326,5\end{array}$ & $\begin{array}{l}271 \\
(3,70)\end{array}$ & 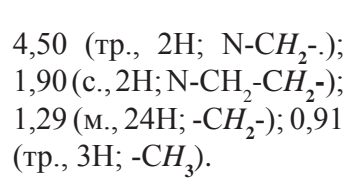 \\
\hline $12 \mathrm{C}_{16} \mathrm{H}_{33}$ & 26 & $145-147$ & 0,71 & $\frac{63,20}{63,48}$ & $\frac{10,72}{10,65}$ & $\frac{16,75}{16,45}$ & $\frac{9,25}{9,41}$ & $\begin{array}{l}341 \\
{[\mathrm{M}+\mathrm{H}]^{+}} \\
\mathrm{MM} \\
340,6\end{array}$ & $\begin{array}{l}273 \\
(3,73)\end{array}$ & $\begin{array}{l}5,61(\text { с., } 1 \mathrm{H} ;-\mathrm{NH}) ; 4,22 \\
\left(\text { с., } 2 \mathrm{H} ;-\mathrm{NH}_{2}\right) ; 3,40(\text { тр., } \\
\left.2 \mathrm{H} ; \mathrm{N}-\mathrm{CH}_{2}-\right) ; 1,65 \quad(\text { с., } \\
\left.2 \mathrm{H} ; \mathrm{N}_{-} \mathrm{CH}_{2}-\mathrm{CH}_{2}-\right) ; 1,27 \\
\left(\text { с., } 2 \mathrm{H} ;-\mathrm{CH}_{2}-\mathrm{CH}_{3}\right) ; 0,87 \\
\left.\text { (тр., } 3 \mathrm{H} ;-\mathrm{CH}_{3}\right) .\end{array}$ \\
\hline
\end{tabular}

различными видами колебаний функциональных групп заместителей. Так, полосы при 3311-3425 и $3271 \mathrm{~cm}^{-1}$ соответствуют частотам асимметричных и симметричных валентных колебаний связей N-Н первичной аминогруппы. Уширенная полоса при 3058-3076 $\mathrm{cm}^{-1}$ отвечает валентным колебаниям N-H иминогруппы. Набор полос при 2961, 2921-2933 и 2850-2863 см-1 характеризует асимметричные и симметричные валентные колебания связей С-H алкильной цепи. Полосы 1633-1639, 1609 и 1541-1544 $\mathrm{cm}^{-1}$ могут быть отнесены к деформационным колебаниям остова и валентным колебаниям связей $\mathrm{C}=\mathrm{N}$.

Введение алкильной цепи не оказывает существенного влияния на положение основной полосы поглощения в электронном спектре алкилированных тиадиазолинов. Так, если 2,5-диамино-1,3,4-тиадиазол поглощает при 267 нм, то при введении алкильных заместителей, полоса поглощения незначительно смещается в область 270 нм.

Нами было показано, что сульфат 2,5-диамино-

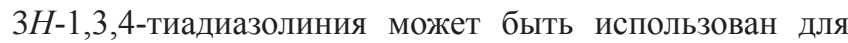
получения 3- $N$-алкилтиадиазолинов (Схема 6). Однако в этом случае выход целевого продукта (23 - 26 \%) ниже по сравнению с алкилированием основания.

Синтезированные алкилтиадиазолины 8, 12 имеют те же характеристики, что и соединения, полученные непосредственно из 2,5-диамино-1,3,4-тиадиазола. ${ }^{[41]}$

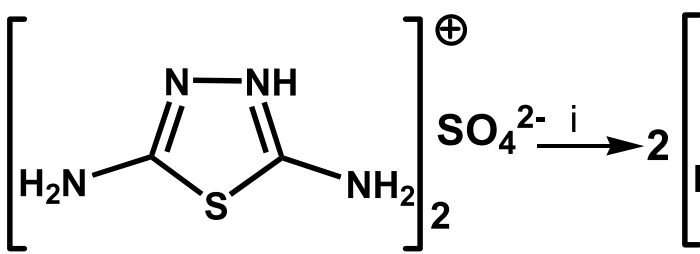

$5 a$<smiles>Nc1nnc(I)s1</smiles><smiles>N=c1sc(N)nn1C=O</smiles>

8,12

i - n-AlkBг, МeOH, 24 час, кип. ii - $\mathrm{NH}_{3}$ водн. $8 \mathrm{Alk}=\mathrm{C}_{5} \mathrm{H}_{11}, 12 \mathrm{Alk}=\mathrm{C}_{16} \mathrm{H}_{33}, \mathbf{A}=\mathrm{Br}^{-}$или $\mathrm{HSO}_{4}$

\section{Схема 6.}




\section{3,5-Диамино-1,2,4-тиадиазол}

Известно, что 3,5-диамино-1,2,4-тиадиазол (13) обладает антигипоксической активностью и применяется в качестве лекарственного средства «Амтизол». Он эффективен при всех формах гипоксии и может быть использован при ожоговом, травматическом и геморрагическом шоке, механической травме, кровопотере, ишемическом и геморрагическом инсульте, расстройстве мозгового и периферического кровообращения, при дыхательной недостаточности, при операциях на сердце и др. ${ }^{[1-4]}$

В основе получения 13 лежит окислительная конденсация 2-имино-4-тиобиурета 14 ${ }^{[42,43]}$ (Схема 7).

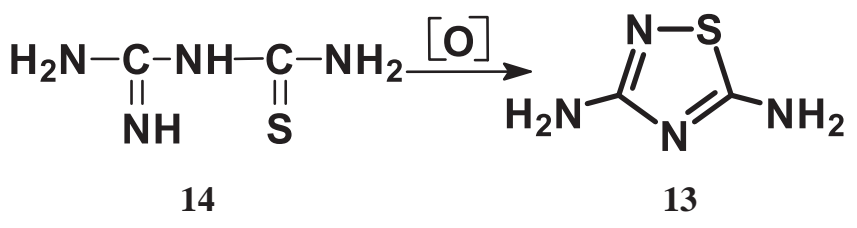

Схема 7.

2-Имино-4-тиобиурет (14) также является лекарственным препаратом «Гутимин», ${ }^{[1-4]}$ а его производные широко применяются не только в фармацевтической, но и в других областях промышленности.

Он обладает широким спектром терапевтического действия, малотоксичен, имеет слабую кумуляцию, оказывает выраженное антигипоксическое действие при разных способах введения. Его высокая эффективность установлена при многих патологических состояниях и заболеваниях, возникновение которых связано с кислородной недостаточностью в организме. ${ }^{[4]}$ Так гутимин рассматривают в настоящее время как эталонный антигипоксант. 2-Имино-4-тиобиурет и его производные обладают радиопротекторными свойствами. [44] Они позволяют получать 66\% норму выживания при облучении смертельными лучевыми дозами. Некоторые производные являются антиоксидантами, т.е. веществами, замедляющими или предотвращающими окислительные процессы, приводящие к старению полимеров, прогорканию пищевых жиров, осмолению топлив и образованию шлама. ${ }^{[45]}$ Производные 2-имино4-тиобиурета аминотиолового ряда являются антигипоксантами - препаратами, улучшающими утилизацию циркулирующего в организме кислорода и уменьшающими гипоксию, повышая тем самым устойчивость организма к различным кислородозависимым патологическим состояниям. ${ }^{[46]}$ Другие же аналоги 2-имино4-тиобиурета применяются в качестве актопротекторов - синтетических препаратов, препятствующих развитию утомления и повышающих работоспособность. ${ }^{[47,48]}$

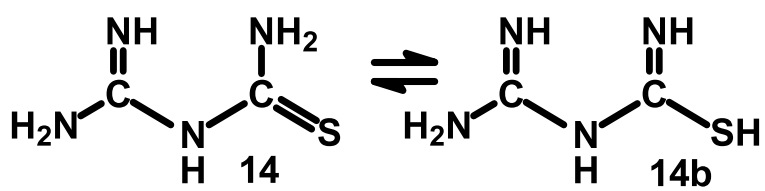

Наиболее распространенный способ получения 14 основан на взаимодействии дициандиамида с газообразным сероводородом. ${ }^{[43,49-51]}$ Нами разработан более простой и удобный способ получения 2-имино-4тиобиурета, заключающийся во взаимодействии дициандиамида с тиосульфатом натрия в присутствии 25\% серной кислоты. ${ }^{[52,53]}$ При этом общий выход продукта повысился с 42\% до 74\% (в пересчете на дициандиамид), а продолжительность синтеза сократилась с 75 до 6 часов. Исключение газообразного сероводорода делает этот метод экологически приемлемым.

\section{Моделирование механизма образования 3,5-диамино-1,2,4-тиадиазола}

К моменту постановки данных исследований вопросы структурной нежесткости 3,5-диамино-1,2,4тиадиазола 12 и 2-имино-4-тиобиурета 14, из которого он получается, в частности, пространственная изомерия, таутомерия, были изучены недостаточно полно. Также оставался нерассмотренным возможный механизм циклизации 2-имино-4-тиобиурета, протекающий под действием пероксида водорода.

Для выявления механизма окислительной конденсации 2-имино-4-тиобиурета, приводящей к образованию 3,5-диамино-1,2,4-тиадиазола, первоначально необходимо изучить геометрические особенности строения и конформационные свойства этой молекулы.

В состав молекулы 2-имино-4-тиобиурета 14 входит сульфидная группировка в совокупности с аминои иминогруппами, принадлежащими тиомочевинному фрагменту, а также гуанильный остаток, что предопределяет склонность данной молекулы к таутомерным превращениям и к внутреннему вращению относительно одинарных связей.

В виду отсутствия в литературе данных об изменении строения данной молекулы при переходе от одной таутомерной формы к другой, нами проведено изучение таутомерных превращений 2-имино4-тиобиурета и свободного внутреннего вращения фрагментов молекулы. Расчеты выполнялись методом DFT с использованием гибридного функционала B3LYP и базисного набора 6-31G(d,p) ${ }^{[54]}$ с помощью программного комплекса PC GAMESS V.7. ${ }^{[55]}$ Подготовка данных для расчета и обработка результатов расчетов осуществлялись с использованием программы ChemCraft. ${ }^{[56]}$ Bсе расчеты выполнены с полной оптимизацией геометрических параметров. Найденные стационарные точки (устойчивые конфигурации и переходные состояния) соответствуют критическим условиям. ${ }^{[57]}$

На первом этапе была изучена амино-иминная и тиол-тионная таутомерия 2-имино-4-тиобиурета (Схема 8).

Схема 8.

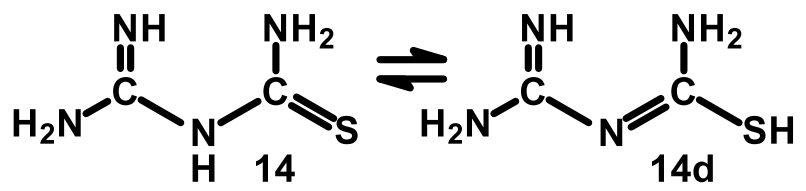




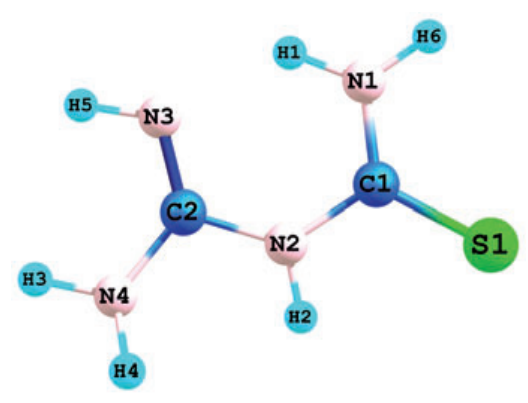

14

$\mathrm{E}_{\mathrm{tot}}=-697.055481$ a.u.

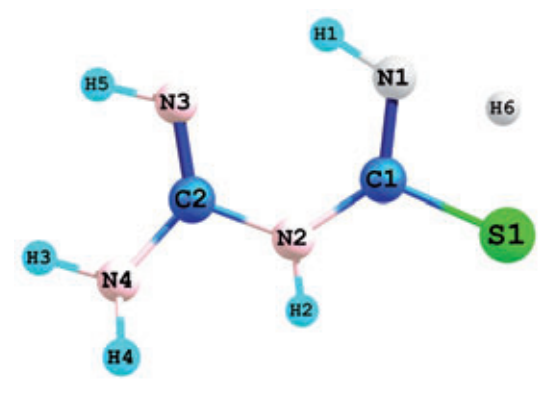

14a

$\mathrm{E}_{\mathrm{tot}}=-696.984336$ a.u.

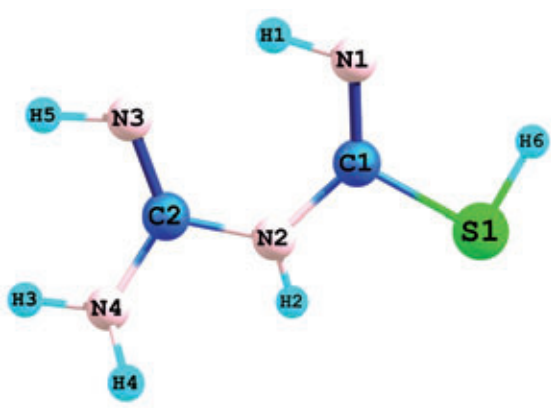

14b

$E_{\text {tot }}=-697.020016$ a.u.

Рисунок 5. Модели и вычисленные значения энергий оптимизированных конфигураций 2-имино-4-тиобиурета (14), переходного состояния (14a) и $N$-(амино(имино)метил)карбамимидосульфониевой кислоты (14b).

Модели оптимизированных конфигураций 2-имино-4-тиобиурета 14, переходного состояния 14a и $\quad N$-(амино(имино)метил)карбамимидосульфониевой кислоты 14b представлены на Рисунке 5.

В исходной молекуле $\mathbf{1 4}$ атом водорода $\mathrm{H}(6)$ удален от серы на $2,804 \AA$. Расстояния C(1)-N(1) и C(1)-S(1) составляют $1,337 \AA$ и $1,681 \AA$ соответственно. Связи $\mathrm{C}(2)-\mathrm{N}(2)$ и $\mathrm{C}(1)-\mathrm{N}(2)$ неэквивалентны. Связь, прилегающая к сульфидной группе, длиннее связи $\mathrm{C}(2)-\mathrm{N}(2)$, соседней с иминогруппой (приблизительно на 0,004 $\AA$ ). Это находится в соответствии с представлениями теории отталкивания валентных электронных пар ${ }^{[58]} \mathrm{o}$ влиянии акцепторного заместителя: если заместитель проявляет бо́льшие электроноакцепторные свойства, то соседняя с ним связь будет длиннее. Угол $\mathrm{N}(1)-$ $\mathrm{C}(1)-\mathrm{S}(1)$ составляет $125^{\circ}$ и близок к таковому для $s p^{2}$ гибридного состояния атома углерода. В переходном состоянии 14а этот угол $\mathrm{N}(1)-\mathrm{C}(1)-\mathrm{S}(1)$ уменьшается до $108^{\circ}$. В таутомере $14 \mathbf{b}$ угол $\mathrm{N}(1)-\mathrm{C}(1)-\mathrm{S}(1)$ практически сохраняет свою величину, соответствующую переходному состоянию, и равен $109,4^{\circ}$, что соответствует значению тетраэдрического угла для углеродного атома в $s p^{3}$-гибридном состоянии. Длина связи С(1)-N(1) приближается к величине двойной связи ${ }^{[13]} 14$ и равна $1,299 \AA$.

В ИК спектре переходного состояния 14а присутствует одна мнимая частота $1617 \mathrm{i} \mathrm{cm}^{-1}$. Спуск по внутренней координате реакции в разных направлениях приводит к реагенту 14 и к продукту $14 \mathrm{~b}$, что подтверждает правильность отнесения данной конфигурации к переходному состоянию. ${ }^{[57]}$ Величина активационного барьера таутомерного превращения $\mathbf{1 4}=>$ 14a составляет 44,64 ккал'моль ${ }^{-1}$ (Рисунок 6). Величина активационного барьера обратного перехода составляет 22,39 ккал'моль ${ }^{-1}$. Полученное значение качественно согласуется с результатами расчетов амино-иминной таутомерии дииминоизоиндолина. ${ }^{[59]}$

Принимая во внимание, что конфигурация 14 энергетически выгоднее конфигурации 14b на 22,25 ккал·моль ${ }^{-1}, 2$-имино-4-тиобиурет должен существовать в газовой фазе преимущественно в форме 14.

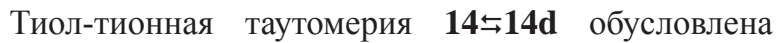
переносом атома водорода $\mathrm{H}(2)$ центральной иминогруппы к атому $\mathrm{S}(1)$ (Схема 7). Модели оптимизированных конфигураций $\mathbf{1 4}$, переходного

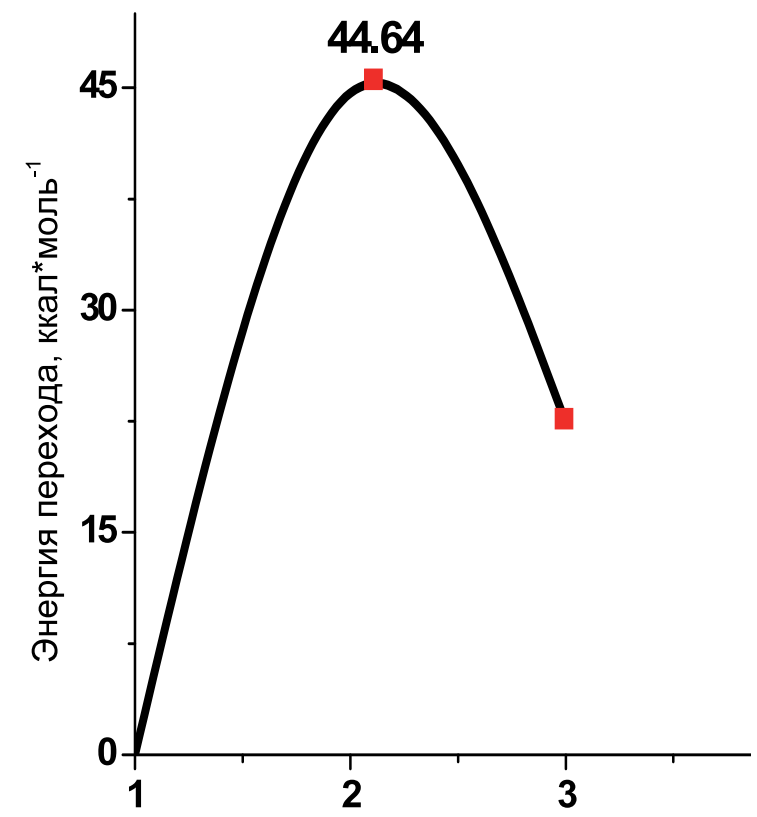

Рисунок 6. Энергетический профиль таутомерных превращений 14 (1) =>14a (2) => 14b (3).

состояния 14c и $N$-(аминомеркаптометилиден)гуанидина 14d приведены на Рисунке 7.

В переходном состоянии мигрирующий протон $\mathrm{H}(2)$ находится в поле атомов азота $\mathrm{N}(2)$ и $\mathrm{S}(1)$. Расстояния $\mathrm{N}(2)-\mathrm{H}(2)$ и $\mathrm{H}(2)-\mathrm{S}(1)$ соответственно равны 1,409 и $1,621 \AA$. Как и для переходного состояния 14a, для 14c угол $\mathrm{N}(2)-\mathrm{C}(1)-\mathrm{S}(1)$ уменьшается по сравнению с 14 до $105,8^{\circ}$.

В таутомере $14 \mathrm{~d}$ неэквивалентность связей $\mathrm{C}(2)-\mathrm{N}(2)$ и $\mathrm{C}(1)-\mathrm{N}(2)$ сохраняется. Расстояние между C(1)-N(1) составляет 1,392 $\AA$, а $\mathrm{C}(2)-\mathrm{N}(2)=1,300 \AA$, угол $\mathrm{N}(1)-$ $\mathrm{C}(1)-\mathrm{S}(1)$ при переходе $14 \mathrm{c}=>\mathbf{1 4 d}$ равен $118^{\circ}$, что делает форму 14d более стабильной, чем 14b. Конфигурация 14d энергетически выгоднее конфигурации 14b на 1,74 ккал·моль ${ }^{-1}$.

В ИК спектре переходного состояния $14 \mathrm{c}$ обнаружена одна мнимая частота $1539 \mathrm{i} \mathrm{cm}^{-1}$. Величина активационного барьера $\mathbf{1 4}=>\mathbf{1 4 c}$ составляет 33,70 ккал·моль ${ }^{-1}$ (Рисунок 8), а обратного перехода $-20,78$ ккал·моль ${ }^{-1}$.

Конфигурация 14 энергетически выгоднее конфигурации $\mathbf{1 4 d}$ на 12,92 ккал·моль ${ }^{-1}$, поэтому и в этом 


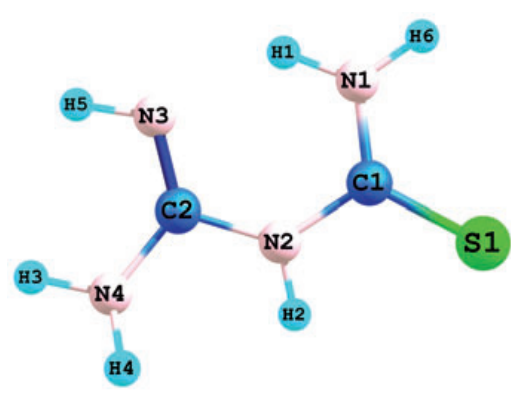

14

$E_{\text {tot }}=-697.055481$ a.u.

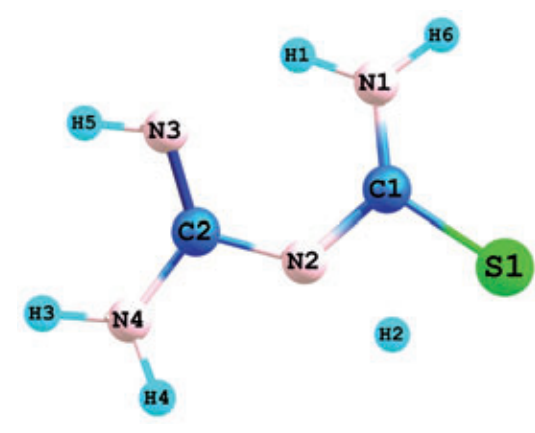

$14 \mathrm{c}$

$E_{\text {tot }}=-697.001769$ a.u.

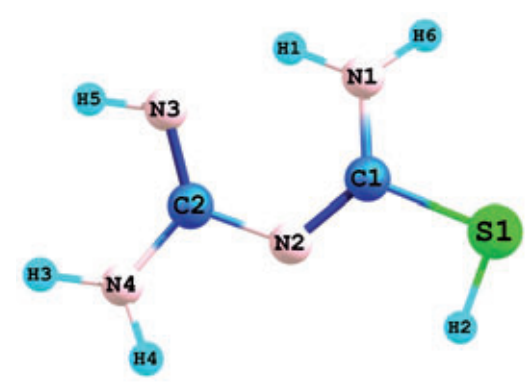

$14 d$

Рисунок 7. Модели и вычисленные значения полных энергий оптимизированных конфигураций 2-имино-4-тиобиурета (14), переходного состояния (14c), $N$-(аминомеркаптометилиден)гуанидина (14d).

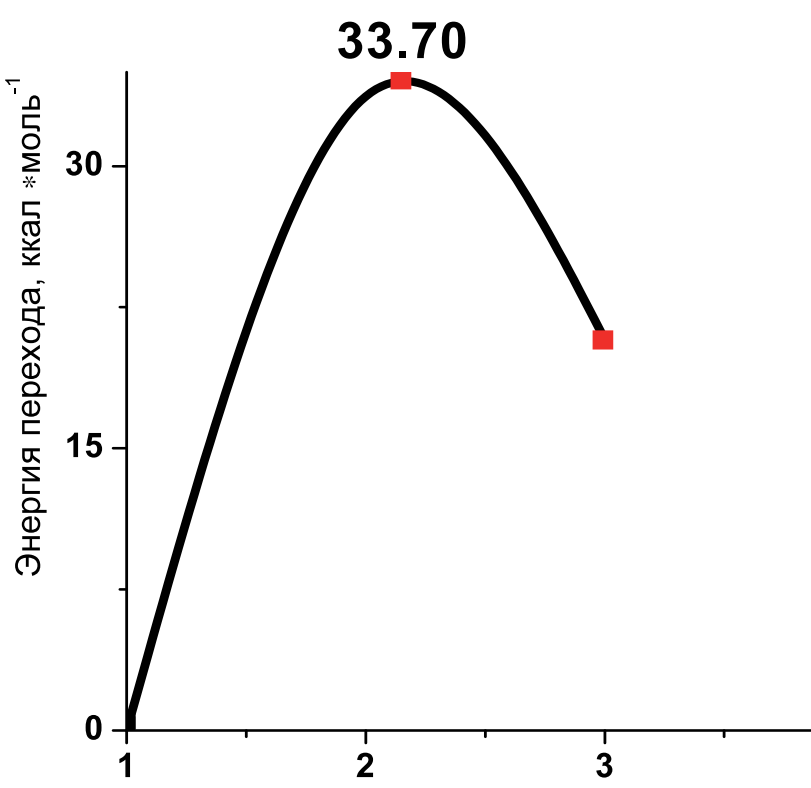

Рисунок 8. Энергетический профиль таутомерных превращений $14(1)=>14 c(2) \Rightarrow$ 14d (3).

случае следует ожидать, что в газовой фазе молекула будет существовать преимущественно в форме 2-имино4-тиобиурета 14.

Таким образом, в газовой фазе более вероятным представляется проявление тиол-тионной таутомерии, т.к. значение энергии активационного барьера последней ниже, чем для амино-иминной таутомерии.

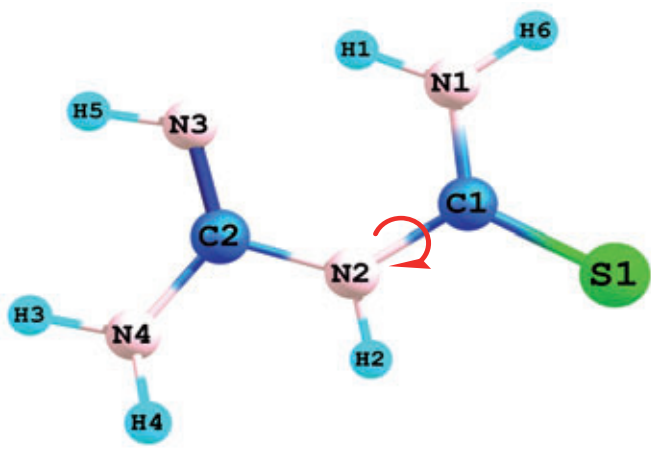

14

$E_{\text {tot }}=-697,055480$ a.u.
Вычисленные термохимические характеристики таутомерных форм и переходных состояний 2-имино-4тиобиурета приведены в Таблице 2.

Таблица 2. Основные термохимические характеристики таутомерных форм 14, 14b,c и переходных состояний 14a,c 2-имино-4-тиобиурета при 298,15 К.

\begin{tabular}{cccc}
\hline $\begin{array}{c}\text { Номер } \\
\text { соединения }\end{array}$ & $\begin{array}{c}\text { Энтальпия } \\
\left(\Delta H_{\mathrm{f}}\right), \text { а.и. }\end{array}$ & $\begin{array}{c}\text { Свободная } \\
\text { энергия }(\Delta G), \\
\text { а.и. }\end{array}$ & $\begin{array}{c}\text { Энтропия } \\
(\Delta S), \\
\text { кал/моль·К }\end{array}$ \\
\hline $\mathbf{1 4}$ & $-696,945623$ & $-696,986276$ & 85,56 \\
$\mathbf{1 4 a}$ & $-696,881155$ & $-696,921553$ & 85,03 \\
$\mathbf{1 4 b}$ & $-696,913633$ & $-696,955104$ & 87,28 \\
$\mathbf{1 4 c}$ & $-696,898890$ & $-696,938977$ & 84,37 \\
14d & $-696,929156$ & $-696,970701$ & 87,44 \\
\hline \multicolumn{2}{c}{ Молекула 2-имино-4-тиобиурета } & имеет две
\end{tabular}
нежесткие координаты, связанные с вращением гуанильного фрагмента вокруг связи $\mathrm{N}(2)-\mathrm{C}(1)$ и вращением тиомочевинного остатка вокруг связи $\mathrm{N}(2)-\mathrm{C}(2)$. Изучение свободного вращения относительно связи С(1)-N(2) в молекуле 14 осуществлялось изменением двугранного угла $\mathrm{S}(1)-\mathrm{C}(1)-\mathrm{N}(2)-\mathrm{C}(2)$ в интервале $(-180-0)^{\circ}$ с шагом $20^{\circ}$ и полной оптимизацией всех прочих параметров. Начальная 14 и конечная 14e конфигурации представлены на Рисунке 9.

Данное вращение приводит к угловой инверсии атома $\mathrm{N}(2)$. Конечная модель 14е является энергетически

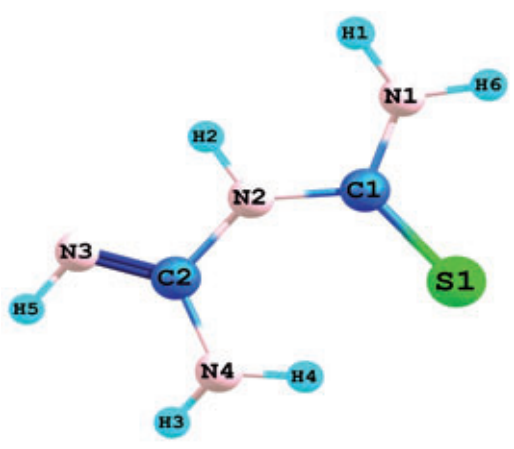

$14 \mathrm{e}$

$E_{\text {tot }}=-697,047965$ a.u.

Рисунок 9. Модели оптимизированных начальной $(\mathbf{1 4})$ и конечной $(\mathbf{1 4 e )}$ конфигураций 2-имино-4-тиобиурета. 
менее выгодной, чем начальная, следовательно, менее стабильной.

В исследованном конфигурационном пространстве внутреннее вращение протекает с преодолением низкого энергетического барьера 4,72 ккал.моль ${ }^{-1}$.

Далее изучалась возможность деформации молекулы 14 за счет изменения двугранного угла $\mathrm{S}(1)-$ $\mathrm{C}(1)-\mathrm{N}(2)-\mathrm{C}(2)$ в интервале $(-180-0)^{\circ}$ с шагом $20^{\circ}$ и полной оптимизацией всех прочих параметров. Активационный барьер внутреннего вращения молекулы относительно связи $\mathrm{N}(2)-\mathrm{C}(2)$ при этом составляет 12 ккал•моль ${ }^{-1}$.

Таким образом, вращение относительно связи $\mathrm{C}(1)-\mathrm{N}(2)$ в молекуле 14 проходит значительно легче с преодолением активационного барьера 4,72 ккал·моль ${ }^{-1}$.

Совокупность полученных результатов позволяет отнести молекулу 2-имино-4-тиобиурета к структурно нежестким. Вклад в структурную нежесткость вносят имино-аминная, тиол-тионная таутомерии в совокупности с внутренним вращением фрагментов молекулы относительно простых связей C-N.

Известно, что реакция циклизации 2-имино-4тиобиурета проходит в результате окислительного действия пероксида водорода. В литературе $\mathrm{e}^{[60,61]}$ на основании кинетических данных реакции окисления 2-имино-4-тиобиурета подкисленными броматами и иодатами смоделирован механизм сложной реакции образования 3,5-диамино-1,2,4-тиадиазола 12, включающий от 9 до 14 уравнений. Ниже приведен механизм окисления 2-имино-4-тиобиурета подкисленными иодатами (Схема 9).

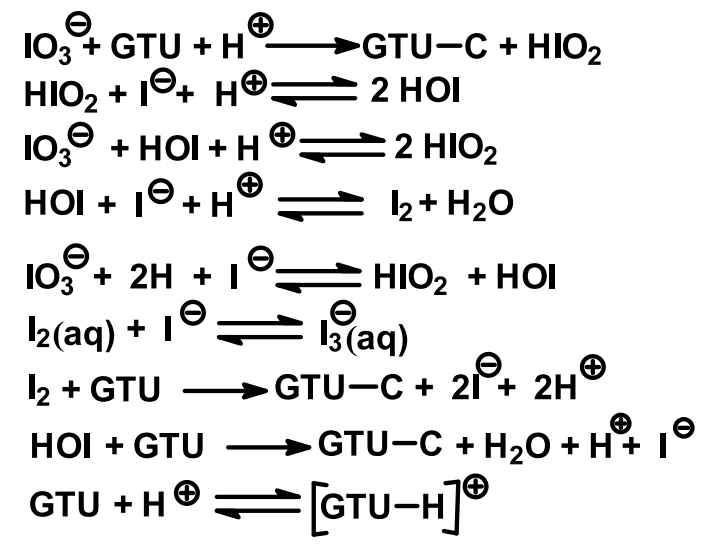

Схема 9. Механизм окисления 2-имино-4-тиобиурета подкисленными иодатами. GTU-C - 3,5-диамино-1,2,4тиадиазол, GTU - 2-имино-4-тиобиурет.

Во всех случаях авторы постулируют, что использование химических, а также природных окислителей, к которым относится пероксид водорода, может приводить к образованию 3,5-диамино-1,2,4тиадиазола. В ходе этих исследований была выяснена стехиометрия некоторых реакций. Однако, механизм реакции, как идентификация физических процессов, составляющих сущность химического превращения, не рассмотрен.

Вместе с тем изучение этого вопроса является важной задачей, т.к. совокупность теоретических и экспериментальных данных позволит приблизиться к пониманиюистинногомеханизмареакцииокислительной конденсации 2-имино-4-тиобиурета.

Предполагаемый механизм данной реакции может быть представлен следующим образом: под действием пероксида водорода циклическая конденсация 2-имино4-тиобиурета (Схема 10) проходит через стадию образования [(аминоиминометил)]амино(гидрокситио)иминометана 14f, который, в свою очередь, отщепляя молекулу воды, превращается в 3,5-диамино-1,2,4тиадиазол 12.

Однако, циклизация промежуточного продукта будет возможна только в случае поворота фрагмента молекулы гидрокситиоиминометана вокруг одинарной связи C-N.

Для моделирования первой фазы механизма образования 3,5-диамино-1,2,4-тиадиазола была выбрана система I, включающая оптимизированную конфигурацию 2-имино-4-тиобиурета 14e и молекулу пероксида водорода. Оптимизированные молекулы реагентов помещались на расстояние $10 \AA$ между реакционными центрами $\mathrm{S}(1)-\mathrm{O}(1)$, которое в интервале $10-4 \AA$ изменялось с шагом $2 \AA$, а затем от $4 \AA$ до $1 \AA$ с шагом $1 \AA \AA$. На каждом шаге проводилась оптимизация всех остальных параметров системы. Было установлено, что в исследованном конформационном пространстве зависимость энергии системы - расстояние $\mathrm{S}(1)-\mathrm{O}(1)$ носит экстремальный характер. Полная оптимизация геометрических параметров (DFT B3LYP/6-31G(d,p)) точки, отвечающей минимуму данной кривой, привела к минимуму поверхности потенциальной энергии (ППЭ) сближения реагентов. Вид, а также характеристики этой конфигурации приведены на Рисунке 10. Анализ распределения зарядов на атомах в I показывает, что нуклеофильная атака углеродного атома C(1), несущего на себе наибольший положительный заряд (0,346 ед.заряда), будет осуществляться атомом кислорода O(1) с зарядом -0,367 молекулы пероксида. Расстояние между атомами $\mathrm{S}(1)$ и $\mathrm{O}(1)$ в предреакционном комплексе I равно $3,422 \AA$, в то время дистанция как между $\mathrm{H}(6)-\mathrm{S}(1)$ составляет 2,282 А. Угол C(1)-N(2)-C(2) равен $129,2^{\circ}$.

В переходном состоянии атомы $\mathrm{S}(1)$ и $\mathrm{O}(1)$ сближены до 2,038 А. Расстояние между атомами кислорода О(1)-О(2) становится равным 1,975 А, между $\mathrm{O}(2)-\mathrm{H}(8)$ соответственно $1,677 \AA$. Сближение атомов $\mathrm{S}(1)$ и $\mathrm{O}(1)$ приводит к образованию ковалентной связи.<smiles>N=C(N)NC(N)=S</smiles>

Схема 10. 


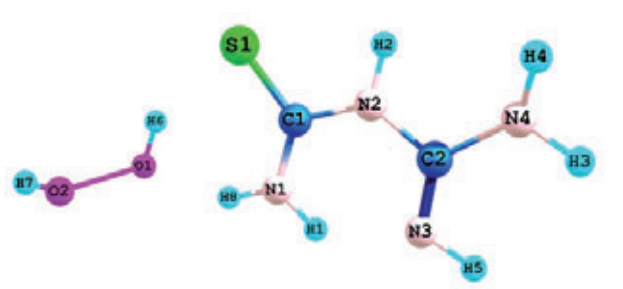

I

$\mathrm{E}_{\mathrm{tot}}=-848.617137$ a.u.

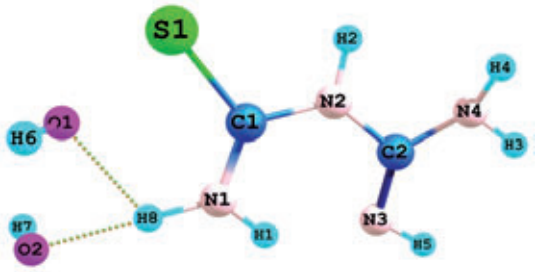

ITS

$\mathrm{E}_{\mathrm{tot}}=-848.569886$ a.u.

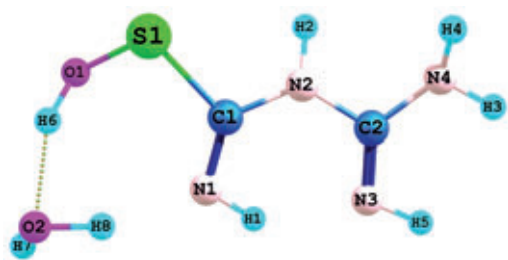

II

$\mathrm{E}_{\mathrm{tot}}=-848.664043$ a.u.

Рисунок 10. Модели предреакционного комплекса I, переходного состояния ITS и конечного продукта II, оптимизированные с помощью метода DFT B3LYP 6-31G(d, p).

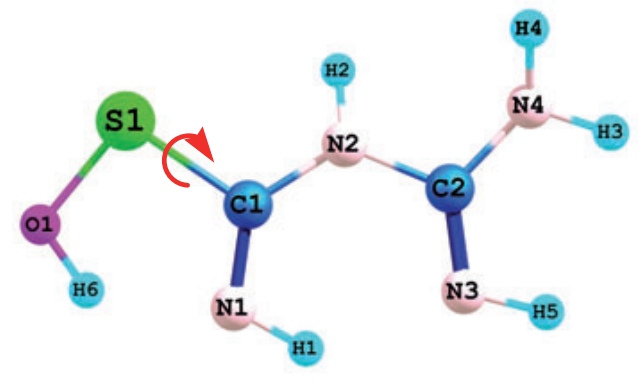

III $\varphi(\mathrm{S} 1-\mathrm{C} 1-\mathrm{N} 2-\mathrm{C} 2)=169^{\circ}$

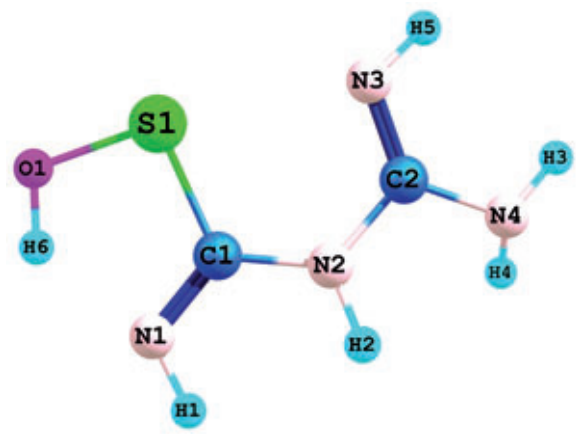

IIIa $\varphi(\mathrm{S} 1-\mathrm{C} 1-\mathrm{N} 2-\mathrm{C} 2)=349^{\circ}$

Рисунок 11. Модели оптимизированных начальной (III) и конечной (IIIa) конфигураций [(аминоиминометил)]амино(гидрокситио)иминометана.

Угол $\mathrm{C}(1)-\mathrm{N}(2)-\mathrm{C}(2)$ равен $128^{\circ}$. Расстояние между $\mathrm{N}(1)-\mathrm{N}(3)$ равно $2,726 \AA$.

В конечном продукте II элементарного химического акта, представленном на Рисунке 10, длина связи $\mathrm{O}(1)-\mathrm{S}(1)$ равна 1,657 $\AA, \mathrm{O}(2)-\mathrm{H}(8)$ соответственно 0,995 $\AA$. Угол $\mathrm{C}(1)-\mathrm{N}(2)-\mathrm{C}(2)$ близок к тетраэдрическому и составляет $126^{\circ}$. Иминогруппы удалены на расстояние $2,837 \AA$.

Основные термохимические характеристики предреакционного комплекса I, переходного состояния ITS и конечного продукта II представлены в Таблице 3.

Энергия активационного барьера I $\Rightarrow$ ITS составляет 59,08 ккал·моль-1. Тепловой эффект реакции равен $-29,65$ ккал моль ${ }^{-1}$.

С целью упрощения последующих расчетов молекула воды была исключена из ІІ. Полная оптимизация геометрии привела к минимуму ППЭ III.

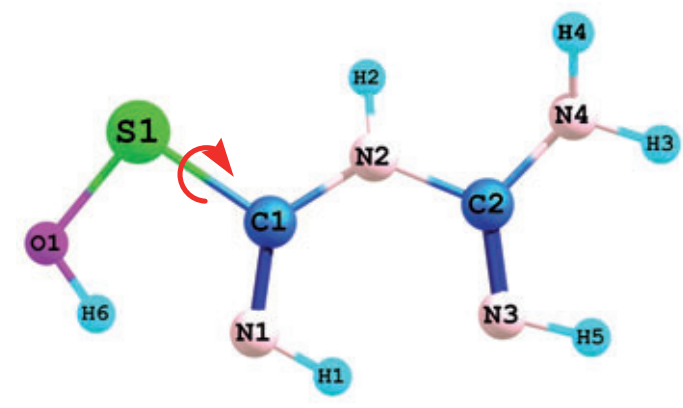

III $\varphi(\mathrm{O}(1)-\mathrm{S}(1)-\mathrm{C}(1)-\mathrm{N}(2))=179^{\circ}$
Таблица. 3. Основные термохимические характеристики предреакционного комплекса I, переходного состояния ITS и конечного продукта II.

\begin{tabular}{cccc}
\hline $\begin{array}{c}\text { Номер } \\
\text { соединения }\end{array}$ & $\begin{array}{c}\text { Энтальпия } \\
\left(\Delta H_{\mathrm{f}}\right) \text {, а.u. }\end{array}$ & $\begin{array}{c}\text { Свободная } \\
\text { энергия }(\Delta G), \\
\text { а.и. }\end{array}$ & $\begin{array}{c}\text { Энтропия } \\
(\Delta S), \\
\text { кал/моль·К }\end{array}$ \\
\hline I & $-848,474130$ & $-848,525555$ & 108,23 \\
ITS & $-848,431569$ & $-848,479089$ & 100,02 \\
II & $-848,522252$ & $-848,571305$ & 103,24 \\
\hline
\end{tabular}

Для осуществления циклизации необходимо, чтобы гидроксигруппа при атоме серы S(1) находилась в транс-положении по отношении к иминогруппе при $\mathrm{N}(2)$. Поэтому следующим этапом моделирования механизма образования тиадиазольного цикла явилось изучение внутреннего вращения ОН-группы относительно связи $\mathrm{S}(1)-\mathrm{C}(1)$ с оптимизацией всех остальных

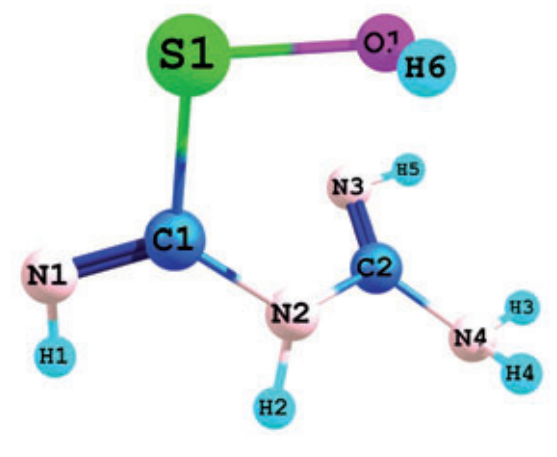

Рисунок 12. Модели оптимизированных начальной (III) и конечной (IIIb) конфигураций [(аминоиминометил)] амино(гидрокситио)иминометана. 


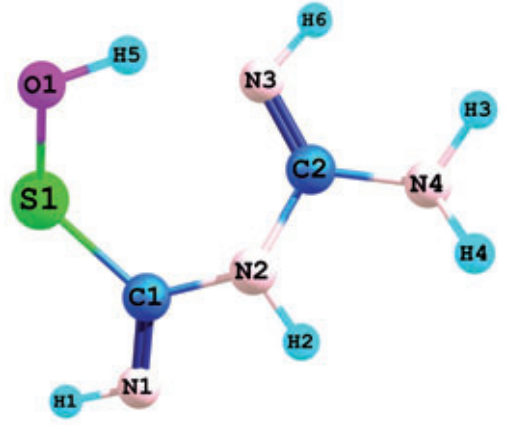

IIIb

-772.222049 a.u.

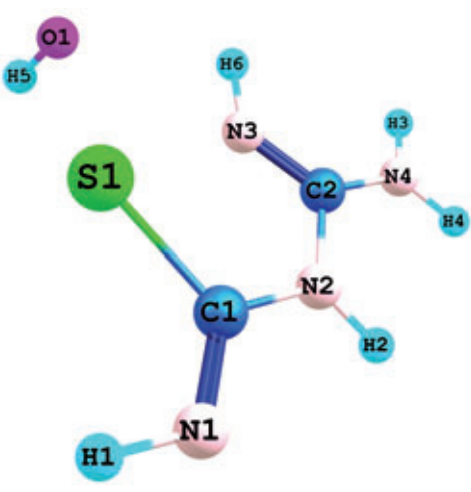

IIITS

-772.158523 a.u. $273 \mathrm{i}$

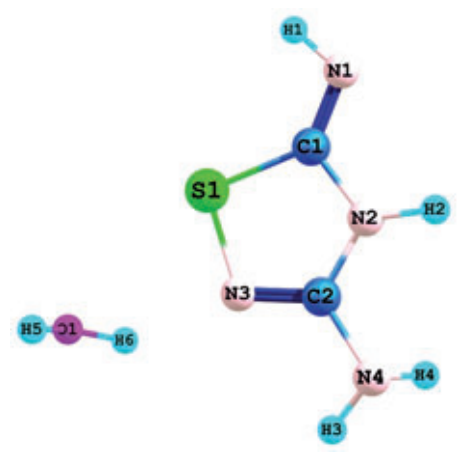

$15 a$

-772.240721 a.u.

Рисунок 13. Модели и вычисленные значения полных энергий оптимизированных конфигураций [(аминоиминометил)] амино(гидрокситио)иминометана (IIIb), переходного состояния (IIITS), системы 3-амино-5-имино-4Н-1,2,4-тиадиазолин-вода (15a).
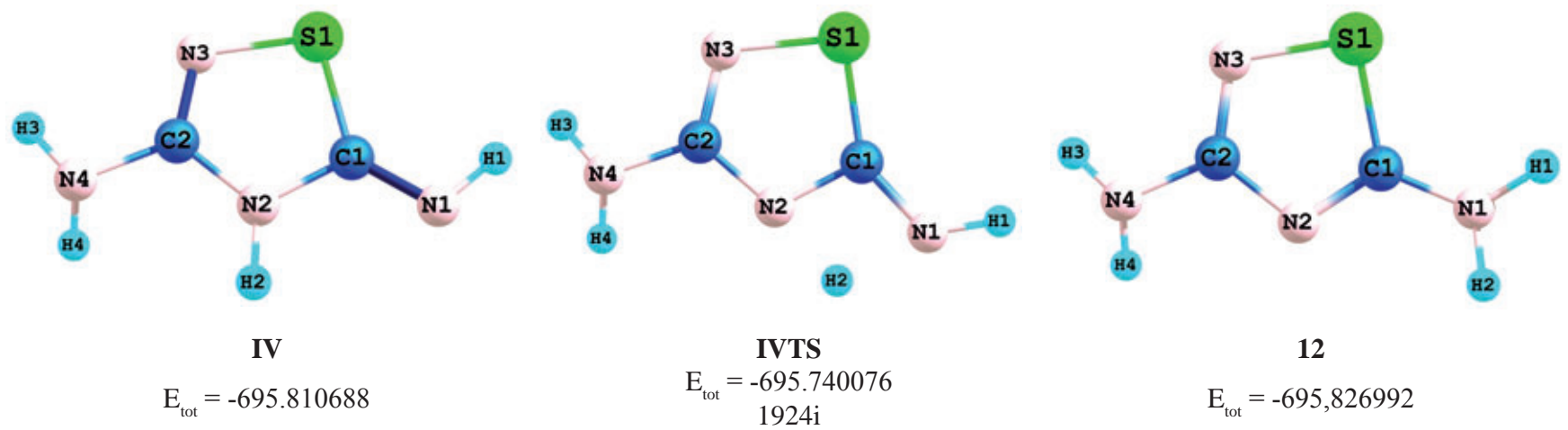

Рисунок 14. Модели и вычисленные значения полной энергии (а.u.) 3-амино-5-имино-1,2,4-тиадиазола IV, переходного состояния IVTS и 3,5-диамино-1,2,4-тиадиазола 12. Геометрия оптимизирована с помощью метода DFT B3LYP 6-31G(d, p).

геометрических параметров молекулы, т.н. мягкое вращение. Модели конформеров III и IIIа представлены на Рисунке 12. Вращение осуществлялось в интервале от $0^{\circ}$ до $180^{\circ}$ с шагом $20^{\circ}$.

Очевидно, что циклизация с образованием тиадиазольного цикла в конформере IIIа не пойдет, т.к. гидроксильная группа и атом водорода Н(5) расположены друг относительно друга в транс-положении.

Второе вращение относительно связи $\mathrm{S}(1)-\mathrm{C}(1)$ осуществлялось в интервале от $180^{\circ}$ до $360^{\circ}$ с шагом $20^{\circ}$. Полученные конформеры III и IIIb, представлены на Рисунке 12.

Вращение проходит с преодолением активационного барьера, величина которого составляет 12,64 ккал·моль-1. Пространственное расположение конформера IIIb предопределяет возможность образования тиадиазольного цикла, поэтому данная модель была использована для дальнейших расчетов при моделировании третьей фазы механизма реакции.

Как и предполагалось ранее, образование 3,5-диамино-1,2,4-тиадиазола 12 может осуществиться за счет отщепления молекулы воды от конформеpa IIIb через переходное состояние IIITS. Модели [(аминоиминометил)]амино(гидрокситио)иминометана (IIIb), переходного состояния (IIITS), системы 3-амино-5-имино-4Н-1,2,4-тиадиазолин-вода (15a), оптимизированных с помощью DFT B3LYP, приведены на Рисунке 13.
Завершающим этапом в моделировании механизма реакции явилось изучение амино-иминной таутомерии продукта реакции IV.

Превращение IV в 12 проходит через переходное состояние IVTS, модель которого приведена на Рисунке 14. Данная конфигурация отвечает требованиям, предъявляемым к критическим точкам ППЭ, и является переходным состоянием: в ИК спектре присутствует одна мнимая частота, равная $1924 \mathrm{i} \mathrm{c}^{-1}$, остальные частоты положительны.

Структуры IV и 12 неплоские, атомы концевых аминогрупп незначительно выведены из плоскости кольца.

Переход из амино-иминной IV в аминоформу 12 осуществляется с незначительным изменением валентных углов и длин связей (Таблицы 4, 5).

Таблица 4. Рассчитанные длины связей (А) 3-амино-5имино-1,2,4-тиадиазола (IV), переходного состояния (IVTS) и 3,5-диамино-1,2,4-тиадиазола (12).

\begin{tabular}{cccc}
\hline Связь & IV & IVTS & 12 \\
\hline $\mathrm{N}(3)-\mathrm{S}(1)$ & 1,727 & 1,728 & 1,699 \\
$\mathrm{C}(1)-\mathrm{S}(1)$ & 1,813 & 1,744 & 1,801 \\
$\mathrm{C}(1)-\mathrm{N}(2)$ & 1,396 & 1,355 & 1,307 \\
$\mathrm{C}(2)-\mathrm{N}(2)$ & 1,381 & 1,369 & 1,381 \\
$\mathrm{C}(2)-\mathrm{N}(3)$ & 1,294 & 1,315 & 1,316 \\
$\mathrm{C}(1)-\mathrm{N}(1)$ & 1,272 & 1,313 & 1,364 \\
$\mathrm{C}(2)-\mathrm{N}(4)$ & 1,385 & 1,376 & 1,377 \\
\hline
\end{tabular}


Таблица 5. Величины углов (град.) 3-амино-5-имино-1,2,4тиадиазола IV, переходного состояния IVTS и 3,5-диамино1,2,4-тиадиазола (12).

\begin{tabular}{cccc}
\hline Угол & IV & IVTS & $\mathbf{1 2}$ \\
\hline $\mathrm{C}(1)-\mathrm{S}(1)-\mathrm{N}(3)$ & 94,43 & 92,42 & 91,35 \\
$\mathrm{~S}(1)-\mathrm{C}(1)-\mathrm{N}(2)$ & 103,89 & 109,19 & 112,33 \\
$\mathrm{~N}(3)-\mathrm{C}(2)-\mathrm{N}(2)$ & 118,49 & 118,42 & 121,26 \\
$\mathrm{C}(1)-\mathrm{N}(2)-\mathrm{C}(2)$ & 114,903 & 112,047 & 108,262 \\
$\mathrm{~N}(3)-\mathrm{C}(2)-\mathrm{N}(4)$ & 123,205 & 121,636 & 123,205 \\
$\mathrm{~S}(1)-\mathrm{C}(1)-\mathrm{N}(1)$ & 131,861 & 145,067 & 133,328 \\
\hline
\end{tabular}

Так при переходе от IV к 12 длина связи N(3)-S(1) уменьшается с 1,727 до 1,699 $\AA$; уменьшение отмечается также и для связи $\mathrm{C}(1)-\mathrm{N}(2)$ с одновременным ростом C(1)-N(1). При этом длина связи C(2)-N(2) не изменяется.

В переходном состоянии IVTS атом водорода Н(2) находится в поле циклического $\mathrm{N}(2)$ и терминального атома $\mathrm{N}(1)$. Расстояния $\mathrm{H}(2)-\mathrm{N}(2)$ и $\mathrm{H}(2)-\mathrm{N}(1)$ соответственно составляют $1,314 \AA$ и $1,404 \AA$.

Величина активационного барьера равна 44,31 ккал•моль ${ }^{-1}$ (Рисунок 15), а для обратного перехода 10,23 ккал·моль ${ }^{-1}$. Диаминная форма 12 энергетически выгоднее амино-иминной формы IV на 34,09 ккал·моль-1, поэтому в газовой фазе она должна преобладать.

Таким образом, в соответствии с предложенным механизмом (Схема 10), образование циклического соединения на пути следования от реагентов к продуктам преодолевает ряд активационных барьеров. Причем стадией, лимитирующей скорость данной реакции, является образование интермедиата II (Схема 11), активационный барьер которой составляет 59,08 ккал моль ${ }^{-1}$.

Предложенный механизм согласуется с кинетическими данными, приведенными в литературе ${ }^{[59,60,62]}$ для реакции окисления 2-имино-4тиобиурета кислыми иодатами и броматами.

\section{Синтез 3,5-Диамино-1,2,4-тиадиазола}

Основным методом получения 3,5-диамино-1,2,4тиадиазола является окисление 2-имино-4-тиобиурета $3-6 \%$ пероксидом водорода ${ }^{[43]}$ в среде метанола и соляной кислоты (Схема 12).

Курцер ${ }^{[43]}$ предложил целевой продукт 13 выделять в виде соли. Такой прием он объяснял тем,

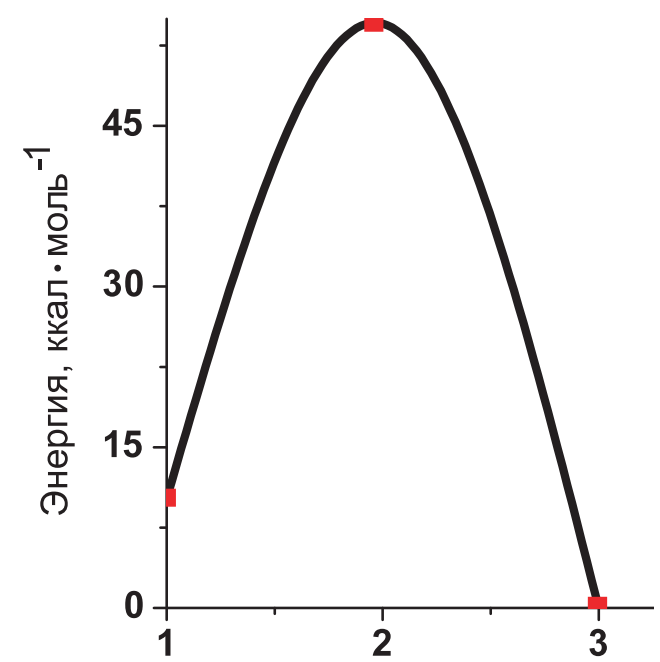

Рисунок 15. Энергетический профиль превращений IV (1) => IVTS (2) => 15 (3).

что образующаяся солянокислая соль 3,5-диамино1,2,4-тиадиазола легко переходит под действием ароматических сульфокислот в соответствующие соли арилсульфонатов, которые легко выделяются и идентифицируются.

В литературе ${ }^{[60-62]}$ авторы показали, что усиление окислительной способности реагента приводит к раскрытию пятичленного цикла с последующим образованием моно-, ди- и триоксида серы, в результате чего образуется гуанилмочевина. Этот вывод подтверждается результатами, описанными в работе [63]. При окислении 2-имино-4-тиобиурета $30 \%$ раствором пероксида водорода наблюдается образование диаминометиленуронид гидросульфата, $\mathrm{C}_{2} \mathrm{H}_{7} \mathrm{~N}_{4} \mathrm{O}^{+} \cdot \mathrm{HSO}_{4}^{-}$. Данное соединение было выделено, и изучена его кристаллическая структура. ${ }^{[63]}$ Таким образом, увеличение концентрации пероксида водорода приводит к снижению выхода целевого продукта.

Производные мочевины легко окисляются перекисью водорода, поэтому перевод их в соль не обязателен, а реакционная среда - этанол с образующейся в результате реакции водой - легко удаляется с помощью вакуумной отгонки или упаривания реакционной массы на водяной бане.

Принимая во внимание выше изложенное, нами разработан достаточно простой в технологическом отношении способ, ${ }^{[64]}$ включающий в себя одну стадию,

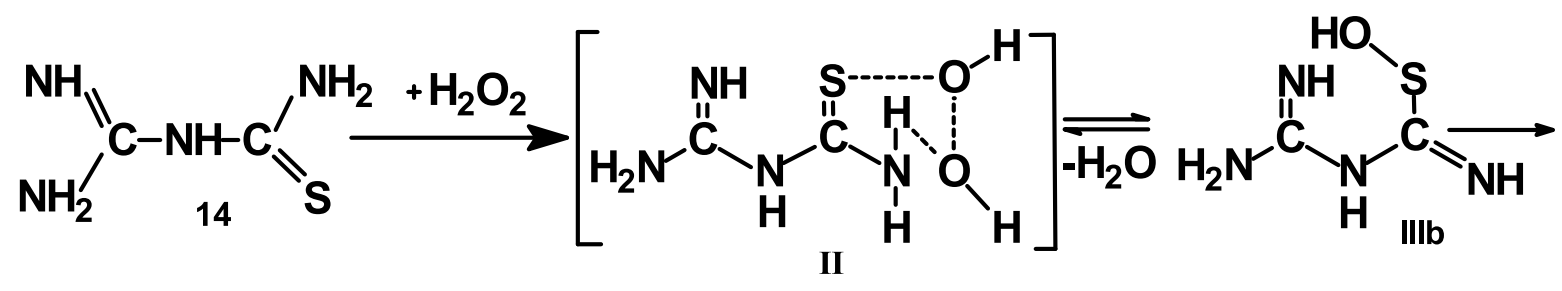<smiles>C=COc1nc(N)ns1</smiles>

Схема 11. 


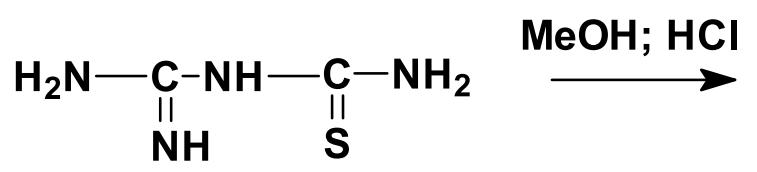<smiles>N=C(N)NC([18OH])=S</smiles><smiles>Cc1ccc(S(=O)(=O)[C@H](Nc2nsc(N)n2)O[C@H](C)c2ccc(S(=O)(=O)[O-])cc2)cc1</smiles><smiles>Nc1nsc(N)n1</smiles>

13

Схема 12.

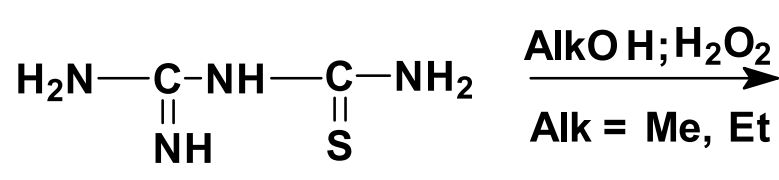

14

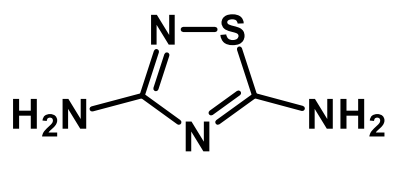

13

Схема 13.

что позволило сократить время синтеза с двух суток до 2 часов (Схема 13).

3,5-Диамино-1,2,4-тиадиазол, полученный по разработанной нами методике, охарактеризован данными электронной, ИК спектроскопии, масс-спектрометрии и данными элементного анализа, которые находятся в соответствии с литературными. ${ }^{[43,61]}$

\section{Список литературы}

\section{References}

1. Semigolovskiy N.Y. Anesteziologiya i Reanimatologiya 1998, 2, 56-59 (in Russ).

2. Smirnov A.V., Krivoruchko B.I. Anesteziologiya $i$ Reanimatologiya 1998, 2, 51-55 (in Russ).

3. Smirnov A.V., Krivoruchko B.I. Anesteziologiya $i$ Reanimatologiya 1997, 3, 97-98 (in Russ).

4. Krapivin S.V, Malishev A.Y., Kharitonov A.V., Ermishina O.S., Shubin S.N., Luk'yanova L.D. Vestnik RAMN 2002, 8, 32-37 (in Russ).

5. Werber G., Buccheri, Gentile M. J. Heterocyclic Chem. 1977, 14, 1263-1265.

6. Danilova E.A, Islyaikin M.K. Izv. Vyssh. Uchebn. Zaved., Khim. Khim. Tekhnol. 1994, 37, 77-81 (in Russ).

7. Islyaikin M.K., Danilova E.A., Yagodarova L.D., RodríguezMorgade M.S., Torres T. Org. Lett. 2001, 3, 2153 - 2156.

8. Islyaikin M.K., Danilova E.A., Kudrik E.V. In: Uspekhi Khimii Porfirinov (Advances in Porphyrin Chemistry) (Golubchikov O.A., Ed.) Snt.-Petersburg: NII Khimii SpbGU 1999, Vol. 2, 300-319 (in Russ).

9. Islyaikin M.K., Borodkin V.F., Danilova E.A., Konovalov S.P., Panov A.A. Izv. Vyssh. Uchebn. Zaved., Khim. Khim. Tekhnol. 1990, 33, 18-21 (in Russ).

10. Danilova E.A., Melenchuk T.V., Islyaikin M.K. In: Allrussian Conference "Prirodnie Makrogeterotsiklicheskie Soedineniya $i$ ikh Sinteticheskie Analogi" ("Natural
Macroheterocyclic Compounds and their Synthetical Analogs") April 2-5, 2007. Russia, Siktivkar, 2007, p. 52 (in Russ).

11. Melenchuk T.V., Danilova E.A., Islyaikin M.K. In: Allrussian Conference "PrirodnieMakrogeterotsiklicheskieSoedineniya i ikh Sinteticheskie Analogi" ("Natural Macroheterocyclic Compounds and their Synthetical Analogs"), April 2-5, 2007. Russia, Siktivkar, 2007, p. 83 (in Russ).

12. Melenchuk T.V., Danilova E.A., Islyaikin M.K. In: $29^{\text {th }}$ Nauchnaya Sessiya po Khimii Porfirinov $i$ ikh Analogov (29th Scientific Session on the Chemistry of Porphyrins and their Analogs), December 26, 2006. Russia, Ivanovo: ISUCT. 2006, p.76 (in Russ).

13. Khimicheskaya Entsiklopediya (Chemical Encyclopedia) (Knunyanst I.L., Ed), Moscow: Sov. Entsikl., 1990, Vol. 1. p. 55 (in Russ).

14. Joule J.A., Mills K. Heterocyclic Chemistry. Blackwell Science, 2004. $728 \mathrm{p}$.

15. Mashkovskii M.D. Lekarstvennie Sredstva (Medicinal Remedies), Moscow: Izdatelstvo Novaya Volna, 2002. 540 p. (in Russ).

16. The Chemistry of Synthetic Dyes (Venkataraman K., Ed.) New York: Academic Press, 1971. 541 p.

17. Taube Karl. Pat. FRG, № 927944, 1955.

18. Ivanskii V.I. Khimiya Geterotsiklicheskikh Soedinenii (Chemistry of Heterocyclic Compounds) Moscow: Vishaya Shkola, 1978. 559 p. (in Russ).

19. Heterocyclic Compounds (Elderfild R., Ed.) New York, 1961, Vol. 7. 467 p.

20. Barton D., Ollis Y. D. Comprehensive Organic Chemistry, Vol. 9: Sulfur Compounds, 1985, 800 p.

21. Busch M. J. Prak. Chem. 193, 124, 301-312 (in Germ).

22. Fromm E. Ann. der Chemie 1922, 426, 313-345 (in Germ).

23. Fromm E. Ann. der Chemie 1923, 433, 1-9 (in Germ).

24. Busch H., Lotz. L. J. Prak. Chem. 1914, 90, 257-273.

25. Hitoshi Senda, Juro Maruha. Acta Cryst. 1987, 43, 347-349.

26. Antolini L., Cornia A., Fabretti A.C., Malavasi J. Crystall. and Spectroscopic Research 1993, 23, 967-971. 
27. Gel'mbol'dt V.O., Ilyukhin A.B., Ganin E.V., Ennan A.A. Rus. J. Coord. Chem. 2001, 27, 573-577.

28. Hitoshi Senda, Hajime Matsuoka, Juro Maruha. Acta Cryst. 1986, C42, 1087-1089.

29. Danilova E.A., Islyaikin M.K., Kolesnikov N.A., Melenchuk T.V. Patent RF № 2313523. B.I., 2007, № 36.

30. Melenchuk T.V., Danilova E.A., Stryapan M.G., Islyaikin M.K., Rus. J. Gen. Chem. 2008, 78, 495 - 499.

31. Stolle R., Fehrebach K. J. Prak. Chemie 192, 122, 289-318 (in Germ).

32. Guha P.C. J. Am. Chem. Soc. 1923, 45, 1036 - 1042.

33. Guha P.C., Mehta D.R. Chem. Abstr. 1939, 33, 598-599.

34. Fromm E., Layer H., Nerr N. Ann. der Chemie 1923, 433, 1-8 (in Germ).

35. Busch M., Holzmann Her. Ber. 1901, 34, 320-345.

36. Busch M., Schmidt R. J. Prak. Chem. 1931, 130, 342-346 (in Germ).

37. Bambas L.L. In: Five-membered Heterocyclic Compounds with Nitrogen and Sulfur or Nitrogen, Sulfur and Oxygen. New York, London: Interscience publishers LTD, 1952, p. 124-142.

38. Werber G., Buccheri, Gentile M. J. Heterocyclic Chem. 1977, 14, 1263-1265.

39. Islyaikin M.K. Sintez, Osobennosti Stroeniya i Svoistva Zameschennikh Makrogeterotsiklicheskikh Soedinenii i ikh Kompleksov s Metallami (Synthesis, Structure Peculiarities and Properties of Substituted Macrohetrocyclic Compounds and their Metallocomplexes). Dis. Dr. Chem. Sci. Ivanovo State University of Chemistry and Technology, 2004. 353 p. (in Russ).

40. Danilova E.A., Melenchuk T.V., Islyaikin M.K. In: 23 ${ }^{\text {nd }}$ International Symposium on Organic Chemistry of Sulfur. June 29 - July 4, 2008. Russia, Moscow. 2008, p. 81-82.

41. Melekhonova E.E., Melenchuk T.V. In: Scientific Conference of the Festival of Students, Post-graduate Students and Young Scientists. April 20-24, 2009. Russia, Ivanovo: Ivanovo State University, Part VIII, 2009, p.53.

42. Tomchin A.B., Etingova N.I., Smirnov A.V., Vainshtein V.A., Munzhukova M.Y., Marysheva V.V., Krivoruchko B. I., Shustov E.B. Pat. 2096043 RF, 1997.

43. Kurzer F. J. Chem. Soc. 1955, 1-6.

44. Stratton K., Davis E.M. Int. J. Radiat. Biol. 1962, 5, 105-121.

45. Zarubina I.V., Mironova O.P., Krivoruchko B.I., Smirnov A.V. Voprosy Biologicheskoi, Medicinskoi i Farmacevticheskoi
Khimii: Kvartal'nyi Nauchno-Practicheskii Zhurnal 2001, 1, 51-55 (in Russ).

46. Marysheva V.V. Obzory po Klinicheskoi Farmakologii i Lekarstvennoi Terapii: Recenziruemyi NauchnoPraktichteskii Zhurnal 2007, 5, 17-27 (in Russ).

47. Bulanov Y.B. Anabolicheskie Sredstva (Anabolic Remedies). 2004. http://bulanoff.ru/anabolic.html.

48. Castro A., Castano T., Encinas A., Porcal W., Gil C. Bioorg. Med. Chem. 2006, 14, $1644-1652$.

49. Baumann E. Ber., 1873, 6, 1371-1377.

50. Sheehan J.C., Buchi G., Knutson D. Organic Syntheses 1963, $4,502-504$.

51. Zasosov V.A., Metelkova E.I., Voljina O.N., Shagalov L.B., Vlasov A.S. Med. Promishlennost 1963, 9, 15-22 (in Russ).

52. Melenchuk T.V., Konovalova E.A., Danilova E.A., Islyaikin M.K. Izv. Vyssh. Uchebn. Zaved., Khim. Khim. Tekhnol. 2008, 51, 125-127 (in Russ).

53. Danilova E.A., Melenchuk T.V., Konovalova E.A., Islyaikin M.K. Accepted Patent Application № 2008131730/04 (039594), September 10, 2009.

54. Kon V. Uspekhi Fiz. Nauk 2002, 172, 336-348 (in Russ).

55. Granovsky A.A. PC GAMESS version 7.1.E (FireFly), build number $5190 \mathrm{http} / / /$ classic.chem.msu.su/gran/gamess/index. html

56. Zhurko G.A. Chemcraft. http://www.chemcraftprog.com/.

57. Minkin V.I., Simkin B.Ya., Minyaev R.M. Kvantovaya Khimiya Organicheskikh Soedinenii. Mehanizmi Reakcii (Quantum Chemistry of Organic Compounds. Reaction Mechanisms) Moscow: Khimiya, 1986. 248 p. (in Russ).

58. Gillespi Er. Model Ottalkivaniya Elektronnikh Par Valentnoi Obolochki i Stroenie Molekul (The Model of Repulsion of Electron Pairs of the Valent Shell) Moscow: Mir, 1992. 296 p. (in Russ).

59. Lybimtsev A.V., Baran'ski A., Islyaikin M.K., Smirnov R.P. Chem. Heterocycl. Comp. 1997, 8, 1074-1079.

60. Chikwana E., Simoyi R.H. J. Phys. Chem. 2004, 108, 10241032 .

61. Chikwana E., Otoikhian A., Simoyi R.H. J. Phys. Chem. 2004, 108, 11592 - 11599.

62. Makarov S.V., Mundoma C., Penn J.H., Svarovski S.A., Simoyi R.H. J. Phys. Chem. 1998, 102, 6786-6792.

63. Hołyńska M., Kubiak M. Acta Crystal. 2008, C64, 609-612.

64. Danilova E.A., Islyaikin M.K., Melenchuk T.V., Syd'ina E.N. Patent RF № 2348623. B.I., 2009, № 7.

Received 22.10.2009

Accepted 25.12.2009

First published on the web 24.03.2010 